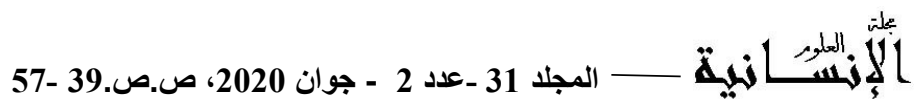

\section{مقارنة تحليلية لمدارس كرة القدم بفرق الاحتراف الجزائرية والتونسية}

\author{
An Analytical Comparison of Soccer Academy \\ Between Algerian and Tunisian professional teams
}

تاريخ الاستلام : 2019/09/03 ؛ تاريخ القبول : 2020/01/06

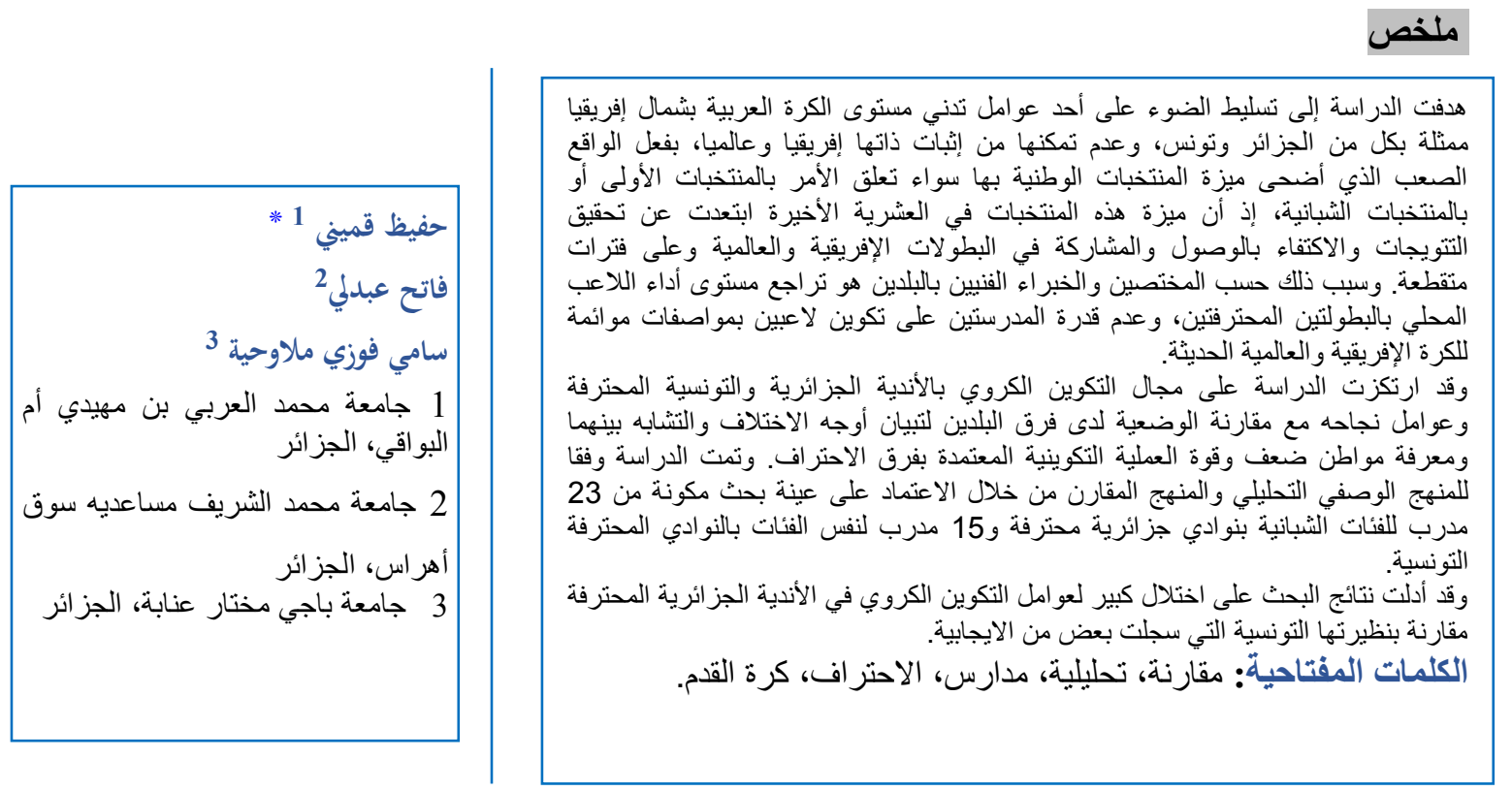

\section{Abstract}

The study aimed to shed light on one of the factors of the low level of Arab football in North Africa represented by Algeria and Tunisia, and its inability to prove itself Africa and Worldwide competition, because of the difficult reality that has become the advantage of national teams, whether it is the first teams or youth teams, as The advantage of these teams in the last decade has moved away from achieving coronations and only to reach and participate in African and international championships and intermittently. The reason for this, according to specialists and technical experts in both countries is the decline in the level of performance of the local player in the two professional tournaments, and the inability of the two schools to train players with specifications compatible with modern African and international football.

The study was based on the field of football training in Algerian and Tunisian professional clubs and its success factors with comparing the situation in the teams of the two countries to show the differences and similarities between them and know the weaknesses and strengths of the training process adopted by professional teams. The study was conducted according to the descriptive and analytical method and the comparative approach by relying on a research sample of 23 trainers for youth groups in Algerian professional clubs and 15 trainers for the same categories in Tunisian professional clubs.

The results of the research showed a significant imbalance of the factors of football formation in the Algerian professional clubs compared to its Tunisian counterpart, which recorded some of the positive.

Keywords: comparison, analytical, schools, professionalism, Soccer.

\section{Résumé}

L'objectif de cette étude est de traiter l'un des paramètres de la baisse de niveau du football algérien ainsi que la situation difficile de l'équipe nationale dont la majorité des joueurs sont formés à l'étranger à défaut de joueurs locaux. Cette situation montre l'échec qui manifeste l'école de football algérienne afin de former des joueurs compétitifs au niveau international.

Notre étude s'articule principalement sur les clubs professionnels et traite les conditions d'une formation footballistique aux normes internationales en comparaison avec la situation en Tunisie en vue de mettre en lumière les ressemblances ainsi que les différences afin de proposer des solutions adéquates et efficaces.

Deux méthodes d'analyse conjointes, la méthode descriptive analytique et la méthode comparative ont été appliquées sur un échantillon composé de 23 entraineurs de petites catégories dans des clubs professionnels algériens et 15 entraineurs de ces mêmes catégories dans des clubs professionnels tunisiens.

Mots clés: Comparaison; Analyse; Écoles; Football; Professionnalisme.

*Corresponding author, e-mail: hafidguemini@gmail.com 


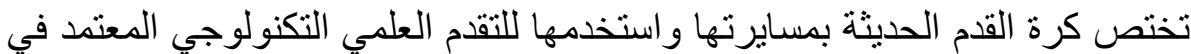

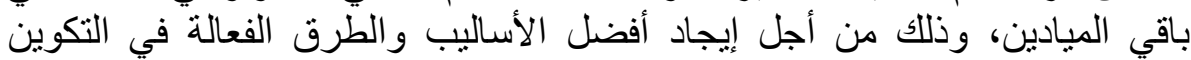

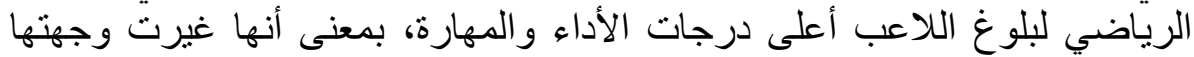

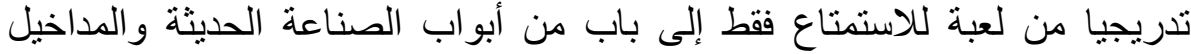

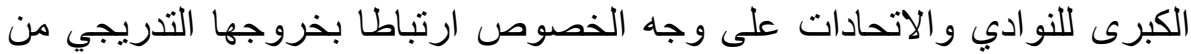

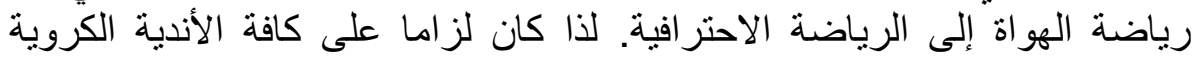

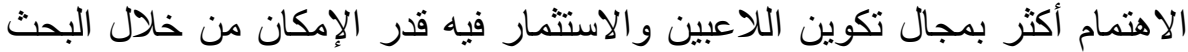

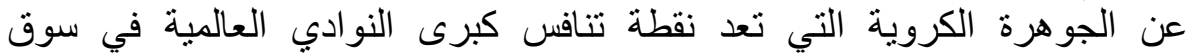

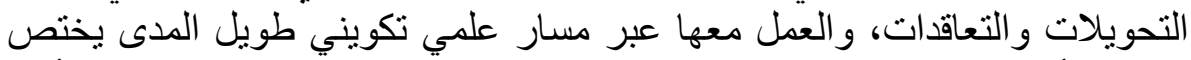

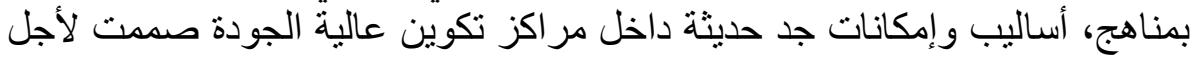
راحة وخدمة الجو هرة الكروية على مدار سنوات ات تكوينها. ولم تنأى كل من الجزائر وتونس هي الأخرى عن مواكية اكبة التغيرات السريعة للعبة

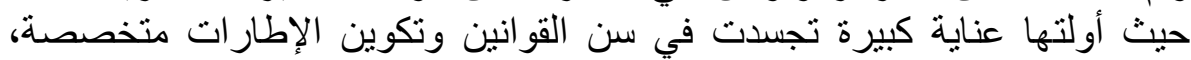

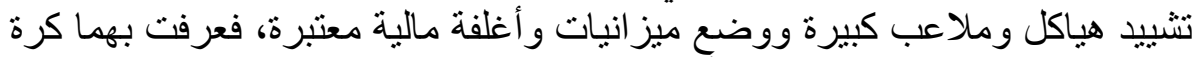

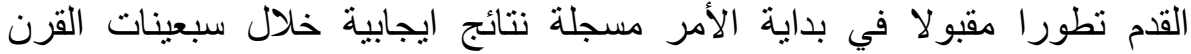

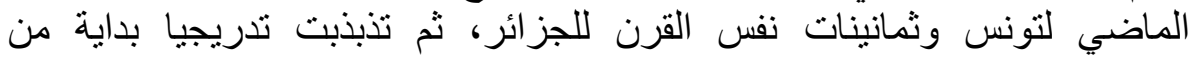

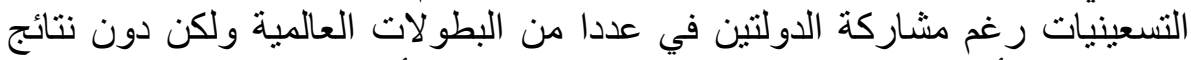
ملفتة عدا تأهل المنتخب الجزائري لثمن نهائي كأس العالم العب العالم بنسخة البرازيل

أولا: الجانب النظري: وضم النئ النقاط المنهجية التالية:

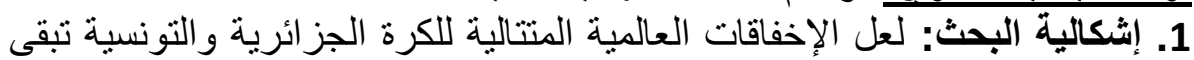

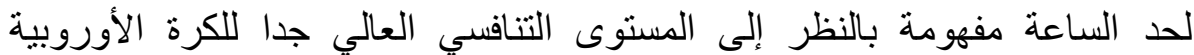

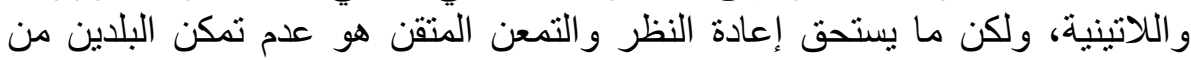

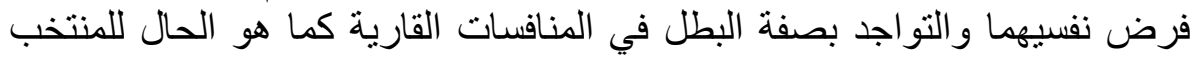

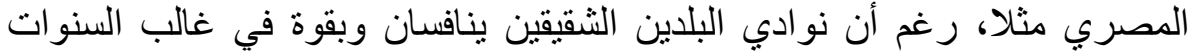

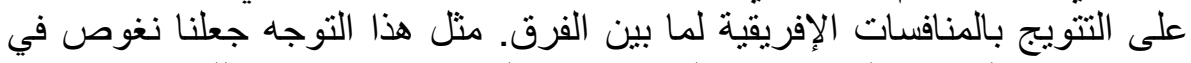

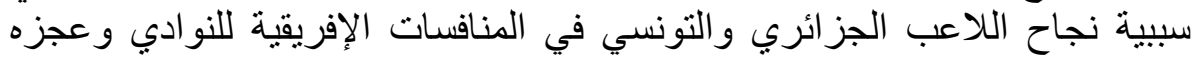

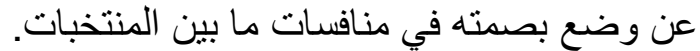

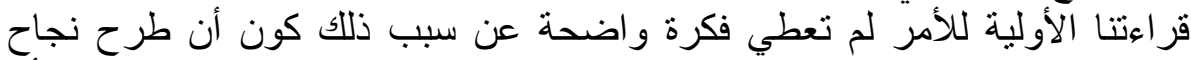

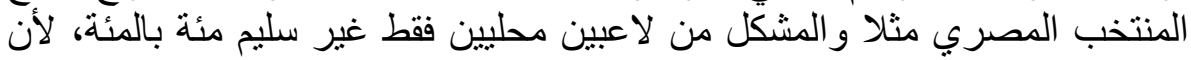

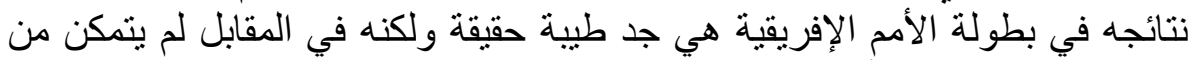

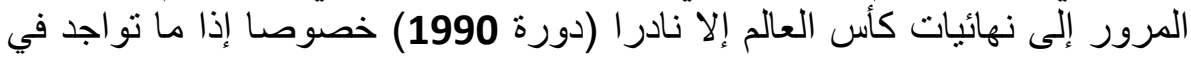

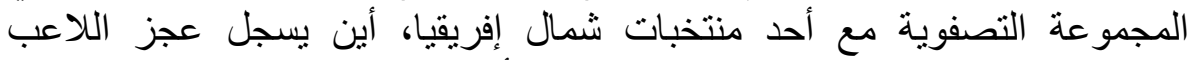

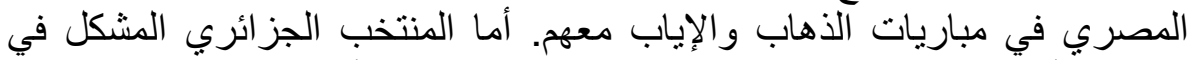

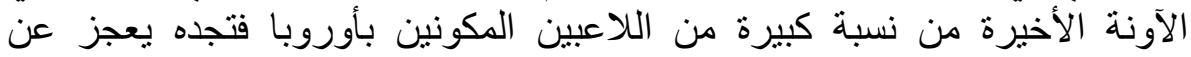

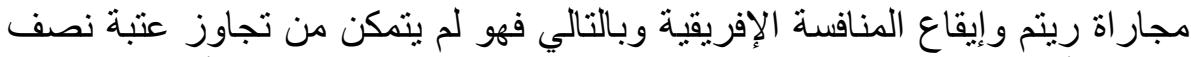

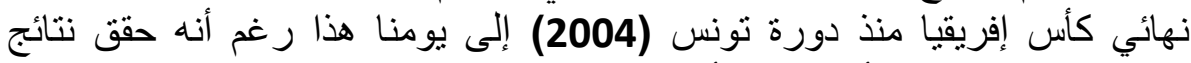

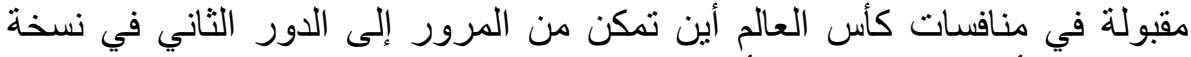

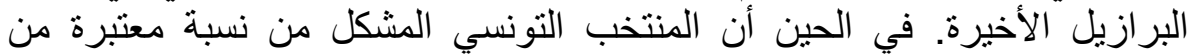

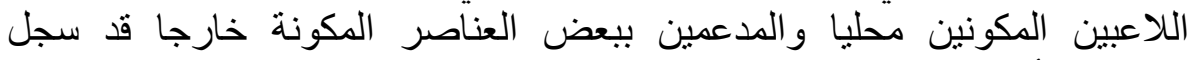

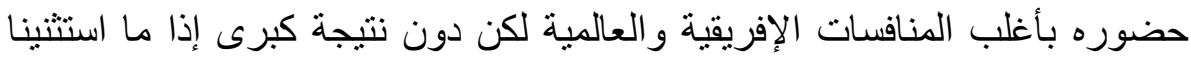

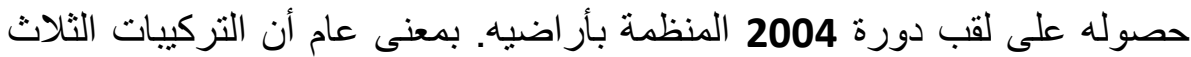


للمنتخبات السالفة الذكر حققت نجاحا نسبيا إفريقيا و عالميا وما نبحث عنه في بحثنا هذا هو نموذج المنتخب المتكامل الذي بإمكانه التنافس على مختلف الجبهات

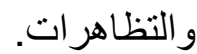
وما بزيد من قيمة المشكل لدينا هو أن إخفاق الكرة الجزائرية والتونسية ارتبط أيضا

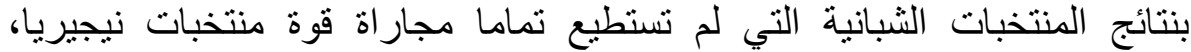

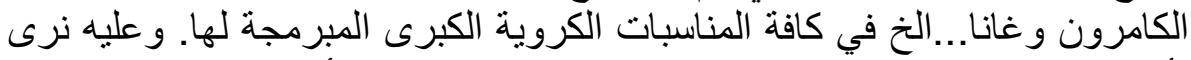

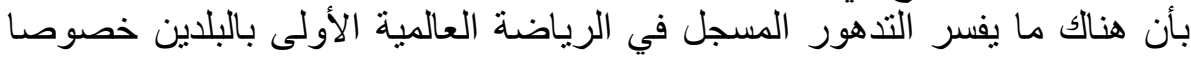

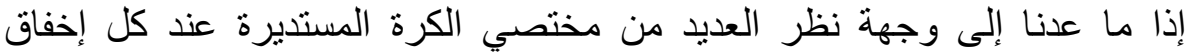

كروي حول ضعف تكوين اللاعب الجزائري و التونسي في الآونة الأخيرة.

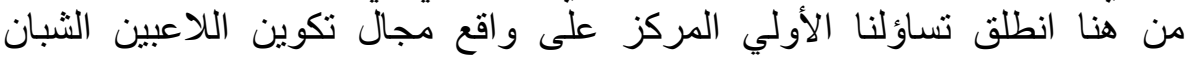

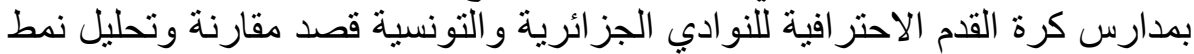
التكوين المعتمد بها ورؤية أيهما أقرب لنماذج التكوين التئ في كبرى الفرق العالميةـ، تحت غطاء التساؤل البحثي التالي:

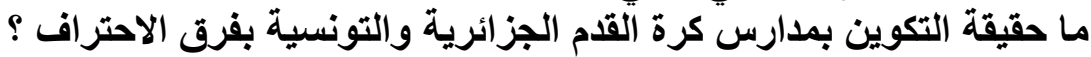

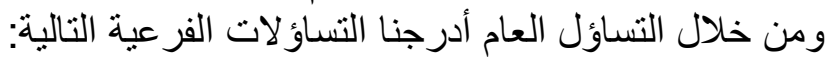
هل هناك اختلاف في واقع التكوين بين مدارس كرة القدم بالأندية

$$
\text { الجز ائرية و التونسية ؟ هل هن }
$$

هل هناك عناية بالمنشات و الهياكل الرياضية بالفئات الصغرى بالأندية

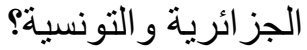

هل هناك اختلاف في تأطير التكوين بين الأندية الجزائرية والأندية

2. فرضيات البحث: للإجابة على أسئلة البحث تم وضع الفرضيات التالية:

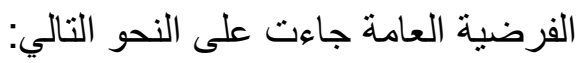

حقيقة التكوين بمدارس كرة القدم الاحترافية الجزائرية والتونسية بعيدة عن

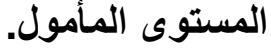

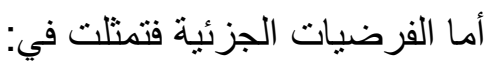

•و اقع التكوين بمدارس نوادي كرة القدم التونسية أفضل منه بالأندية الجز ائرية. •الفئات الصغرى بالأندية الجز ائرية والتونسية تعاني من نقص في المنشات و الهياكل

$$
\text { الرياضية. }
$$

$$
\text { • تأطير التكوين بالأندية الجزائرية و التونسية جد متماتل. }
$$

$$
\text { 3. أهداف البحث:يهدف البحث إلى: البئ }
$$

كم التعرف الفلى على واقع التكوين الكروي بمدارس الاحتراف للنوادي الجزائرية

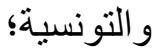
كه معرفة حقيقة الأسباب التي أدت إلى عدم نجاح التكوين الكروي بالجزائر وتونس وتسجيل نقط ضعفه؛ كم معرفة العمليات و الخطوات الواجب اتخاذها لإيجاد الحلول الكفيلة للرفع من مستوى التكوين الرياضي بالبلدين.

4. أهمية البحث: هناك مجمو عة من النقاط جعلت من الدراسة الآتية ذات أهمية بالغة لاكتشاف حقيقة الإمكانيات البشرية والمادية المتوفرة لدى النوادي الكروية و المتمثلة في: الجز ائرية و التونسية وتوجيه استغلالها مستقبلا في تكوين الفئات الثبانية؛ 
ل الاستفادة الميدانية من حيثيات التكوين وتصحيح مساره وفقا لمتطلبات الكرة

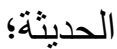

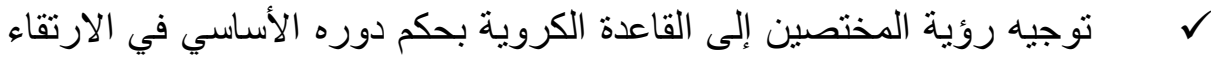
برياضة كرة القدم.

5. منهجية البحث: اعتمد البحث على المنهج الوصفي التحليلي و المنهج المقارن،

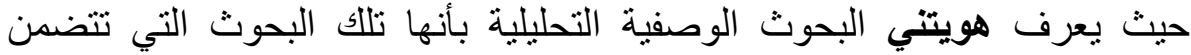
در اسة الحقائق الراهنة المتعلقة بطبيعة ظاهرة ما أو موقف أو مجموعة الوقة من الناس

والأوضاع. (محمد منير حجاب، 2002)

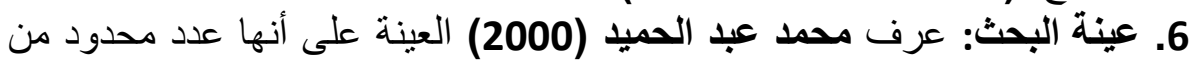
المفردات التي سيتعامل معها الباحث منهجيًا، تعد كمعاينة جزئية تمكن في في نهاية الئية

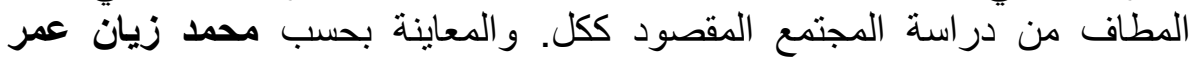

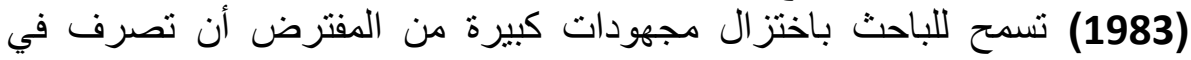

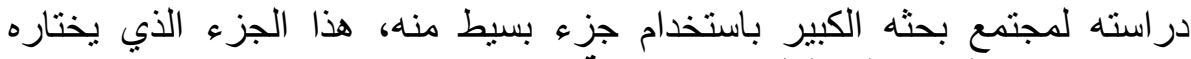

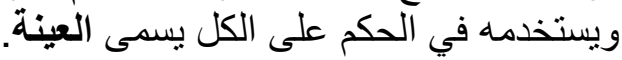

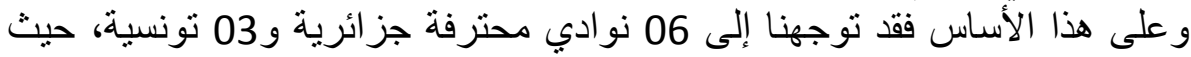

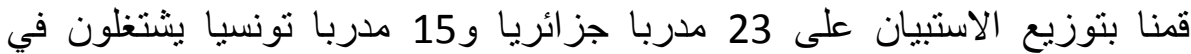

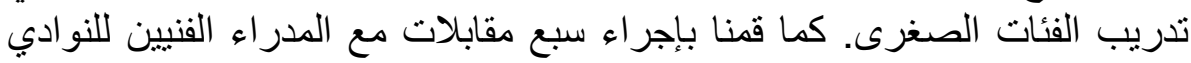

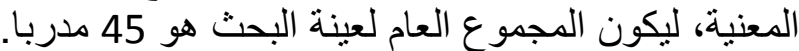
7. أدوات البحث: اعتمد البحث على ثلاث الثية أدوات أساسية للإجابة على تساؤلاتها

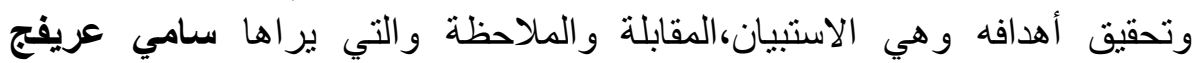
وآخرون (1999) من وسائل البحث الثائعة الاستخدام في البحوث النفانة و الاجتماعية و التربوية:

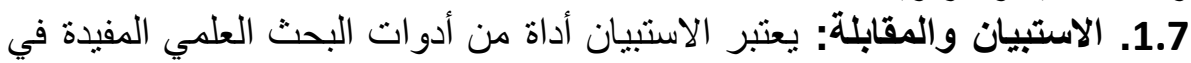

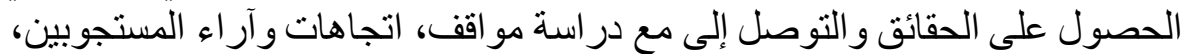

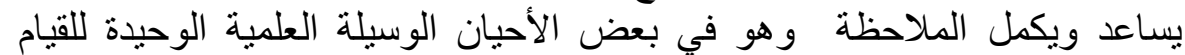

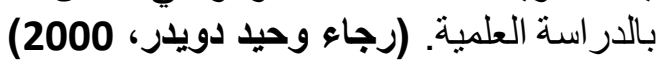

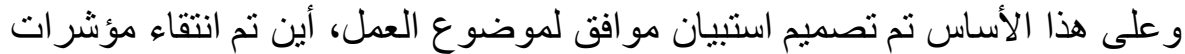

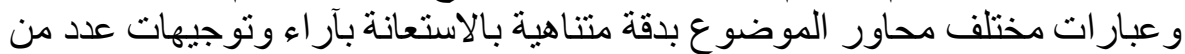

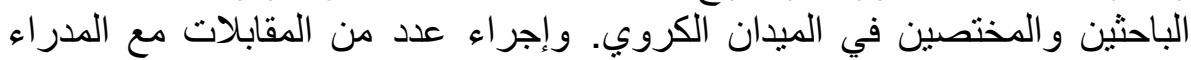

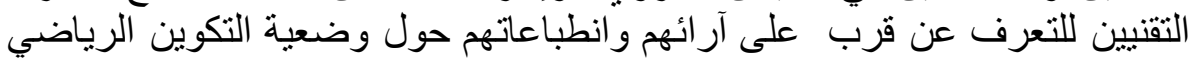
للفئات الصغرى بالبلدين الثقيقين. 2.7. الملاحظة: تمت عن طريق الفيديو حيث قمنا بتصوير الحصص التدرينية

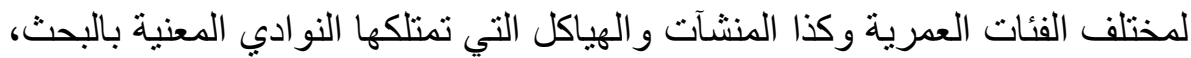
بالإضافة إلى حضور وتسجيل بعض الاجتماعات التقنية بين المدراء الفنبين ومدربي الفئات الثنابة. 3.7. الأدوات الإحصائية: استخدم البحث أهم الأدوات الإنداتئة الإنصائية الملزمة في

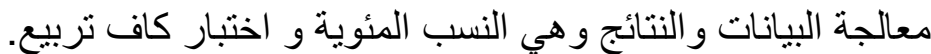

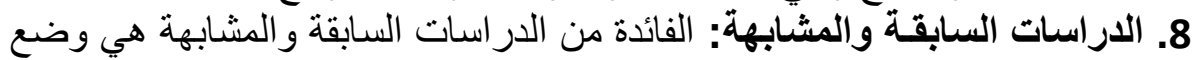

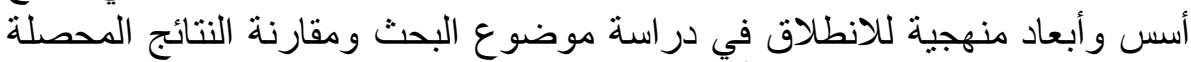

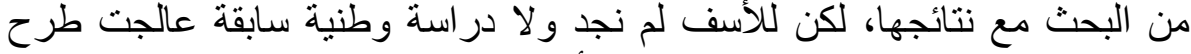

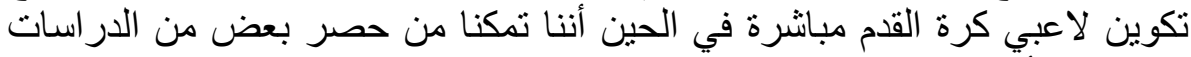
المشابهة الأجنبية و التي نوجز القي هبا في الآتي: 


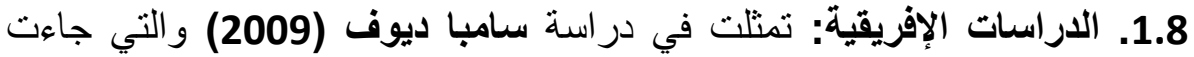

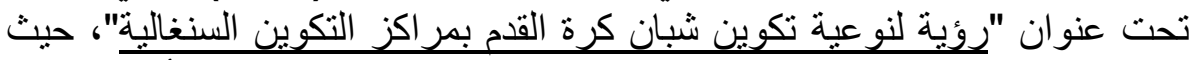

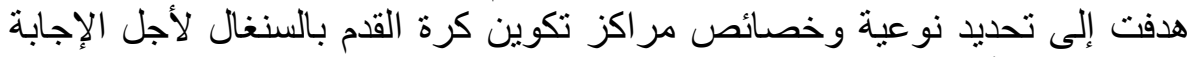

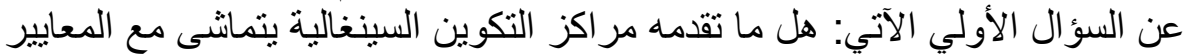

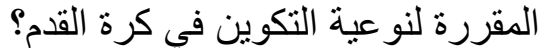

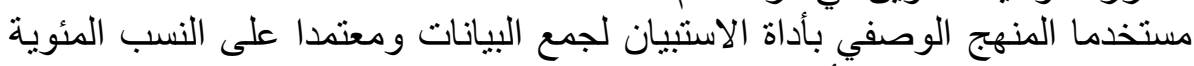

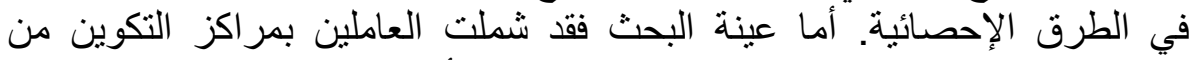
مسؤولين، مدربين وحتى لاعبين بمر اكز التكوين الأربعة التالية : ديامبارس، نجوم

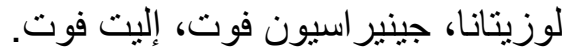

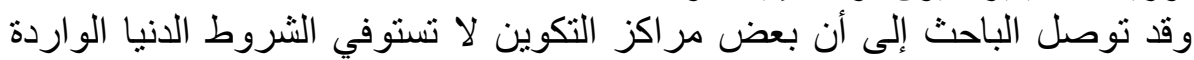

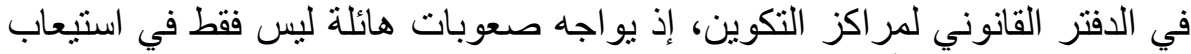
وإطعام الصغار بل أيضا في حالة الملاعب المتوفرة التهرة بها مما يصعب من ممارسة

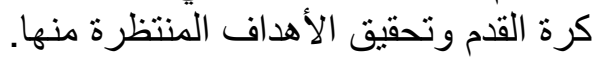

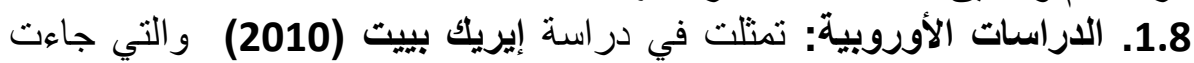

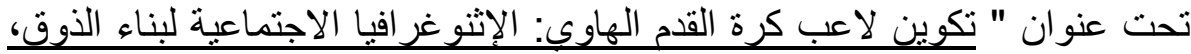

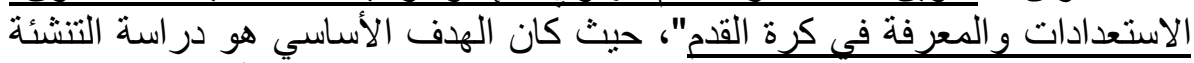

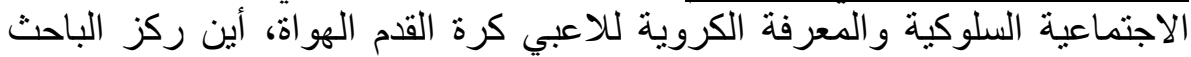

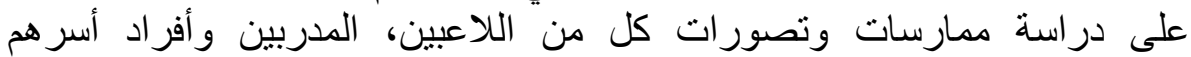

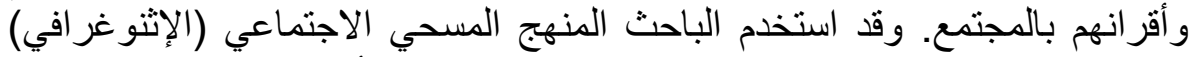

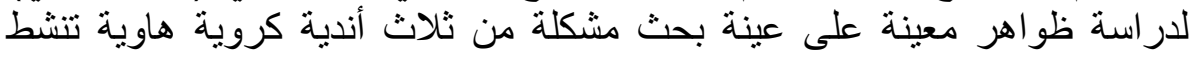

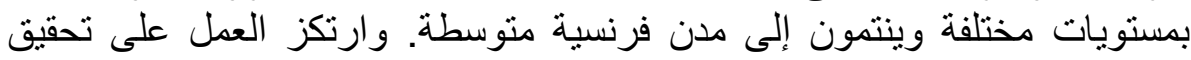

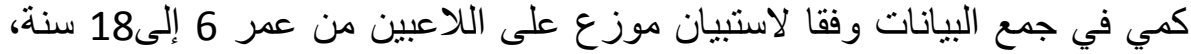

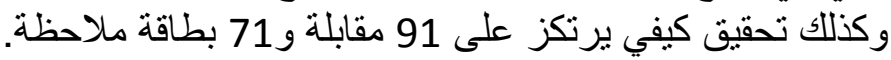

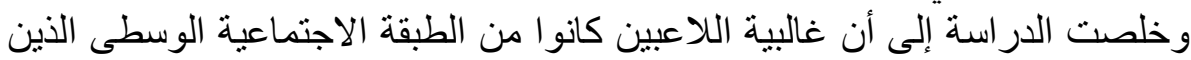

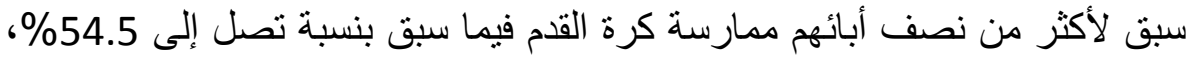

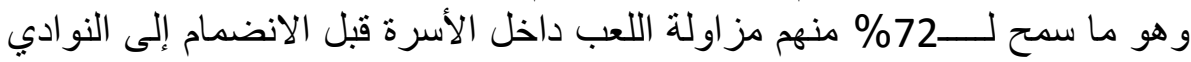

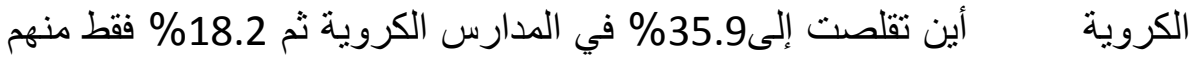

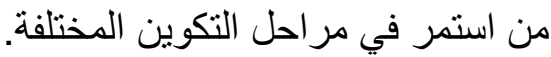
1. ثانيا: الجانب التطيقي للبحثة:

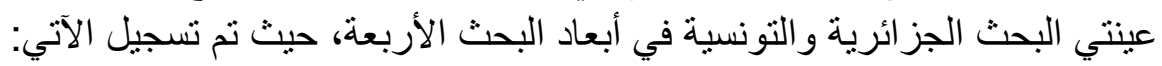

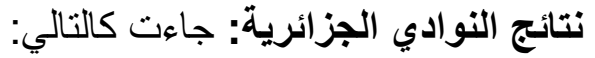

1.1.1. نتائج المحورين الأول والثاني بالأندية الجزائية الترية: عرفت في مجملها نتائج

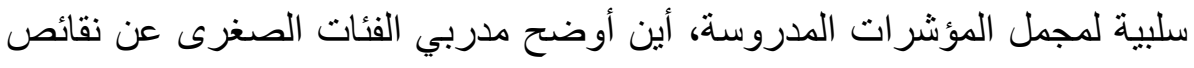


جدول رقم (01): يمثل بعض من نتائج المحورين الأول و الثاني.

\begin{tabular}{|c|c|c|c|c|c|}
\hline $\begin{array}{r}\text { القرار } \\
=05 ، 0 \\
\alpha\end{array}$ & $\begin{array}{r}\mathbf{K i}_{\mathbf{2}} \\
\text { الجدولية }\end{array}$ & $\begin{array}{r}\mathbf{K i}{ }^{2} \\
\text { المحسوبة }\end{array}$ & التكرار & العبارات & المؤشر \\
\hline \multirow[t]{4}{*}{ دال } & \multirow[t]{4}{*}{$81 ، 7$} & \multirow[t]{4}{*}{$94 ، 19$} & 41 & في تر اجع & \multirow{4}{*}{ الأندية } \\
\hline & & & 01 & في تحسن & \\
\hline & & & 07 & متوسط & \\
\hline & & & 01 & لا إجابة & \\
\hline \multirow[t]{4}{*}{ دال } & \multirow[t]{4}{*}{7.81} & \multirow[t]{4}{*}{17.15} & 03 & نعم & \multirow{4}{*}{ ميزانية } \\
\hline & & & 14 & $\gamma$ & \\
\hline & & & 05 & أحيانا & \\
\hline & & & 01 & لا إجابة & \\
\hline \multirow[t]{4}{*}{ دال } & \multirow[t]{4}{*}{$81 \cdot 7$} & \multirow[t]{4}{*}{$68 ، 141$} & 22 & غياب & \multirow{4}{*}{ التكوين } \\
\hline & & & 22 & بالفئات الاهتمام & \\
\hline & & & 22 & غياب التأطير & \\
\hline & & & 01 & لا إجابة & \\
\hline
\end{tabular}

من خلال النتائج المحصل عليها في الجدول السابق والمعبرة عن المؤشرات التالية:

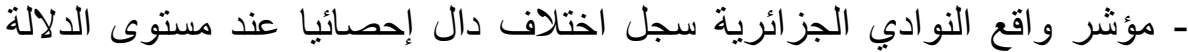

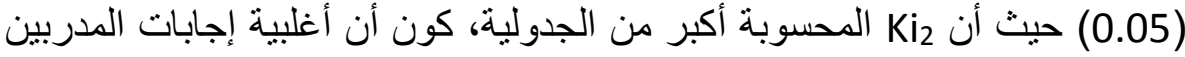

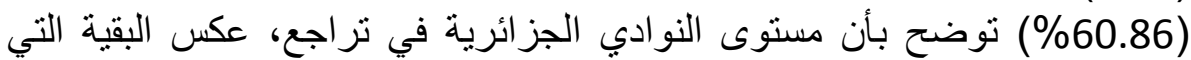

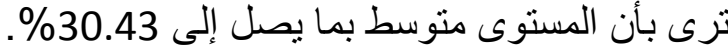

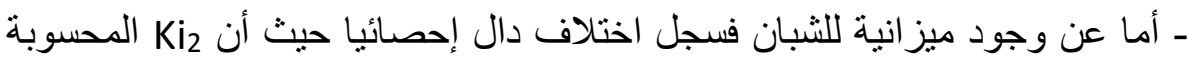

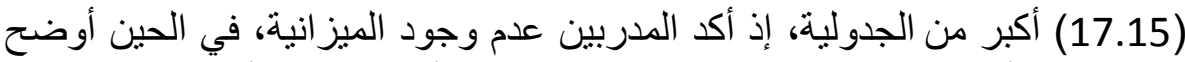

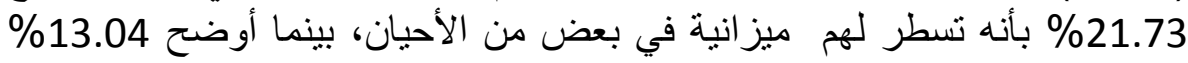
وجودها على مستوى نو اديهم.

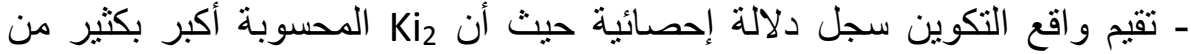

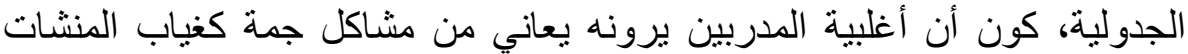

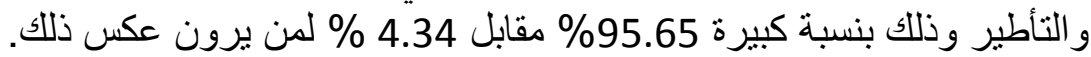

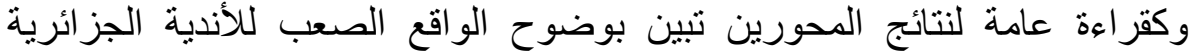
و الذي أثر بشكل مباثر على تكوين اللاعبين، فهي تعاني من مشاكل عديدة منها 
غياب المنشآت، نقص التأطير وعدم تخصيص الدعم المادي للشبان انعكست بالسلب

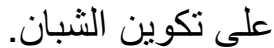

2.1.1. نتائج المحورين الثالث والرابع بالأندية الجزائرية: هي الأخرى في مجملها

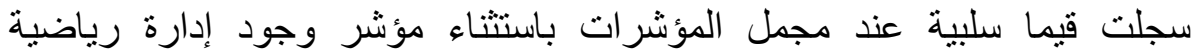

مختصة و الذي كان أفضل بقليل من البقية، حيث أوضح مدربي التئل العينة الآتي ذكره:

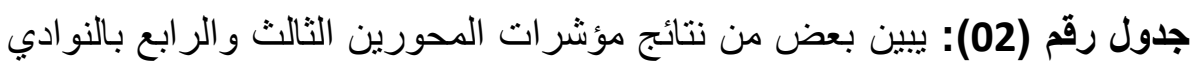

\begin{tabular}{|c|c|c|c|c|c|}
\hline 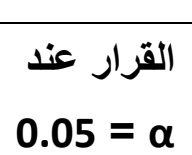 & $\begin{array}{r}\mathbf{K i}_{\mathbf{2}} \\
\text { الجدولية }\end{array}$ & $\begin{array}{r}\mathbf{K i}_{2} \\
\text { المحسوبة }\end{array}$ & التكرار & الأجوبة & المؤشز ائريــ. \\
\hline \multirow[t]{3}{*}{ غير دال } & \multirow[t]{3}{*}{$99 \cdot 5$} & \multirow[t]{3}{*}{$38 \cdot 1$} & 09 & نعم & \multirow{3}{*}{ الصارئ لإضئات } \\
\hline & & & 09 & $y$ & \\
\hline & & & 05 & أحيانا & \\
\hline \multirow[t]{3}{*}{ دال } & \multirow[t]{3}{*}{$99 \cdot 5$} & \multirow[t]{3}{*}{8.28} & 06 & نعم & \multirow{3}{*}{ ومراس } \\
\hline & & & 17 & $\gamma$ & \\
\hline & & & 00 & أحدهم & \\
\hline \multirow[t]{3}{*}{ دال } & \multirow[t]{3}{*}{$99 \cdot 5$} & \multirow[t]{3}{*}{9.7} & 14 & نعم & \multirow{3}{*}{ تقبي } \\
\hline & & & 05 & $\underline{y}$ & \\
\hline & & & 04 & أحيانا & \\
\hline \multirow[t]{4}{*}{ دال } & \multirow[t]{4}{*}{$81 \cdot 7$} & \multirow[t]{4}{*}{$81 ، 8$} & 11 & من 1 إلى & \multirow[t]{4}{*}{ الاجنداعات } \\
\hline & & & 02 & الى64 & \\
\hline & & & 03 & أكثر من & \\
\hline & & & 07 & لا توجد & \\
\hline
\end{tabular}

من خلال النتائج المحصل عليها في الجدول رقم (02) تجلى مايلي:

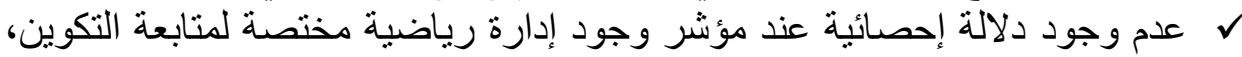

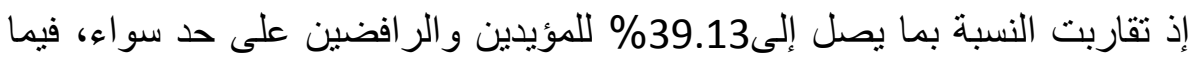


تذهب 21.73\% إلى القول بأن إدارة المتابعة تحضر في بعض الأحيان فقط كبداية الموسم مثنلا.

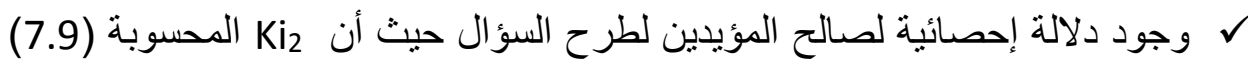

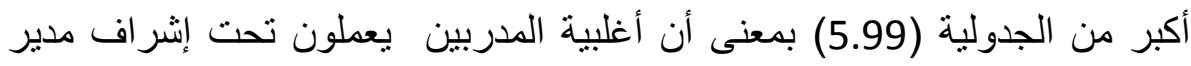
تقني. عدد الاجتماعات المنعقدة سنويا سجلنا به دلالة إحصائية لصالح المجموعة الأولى الصى

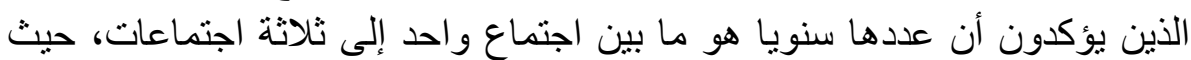

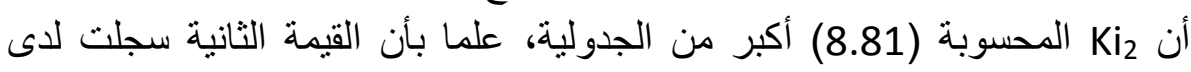
المدربين المؤكدين على عدم برمجة أبي اجتماع تقني سنويا بعدد 7 إجابات.

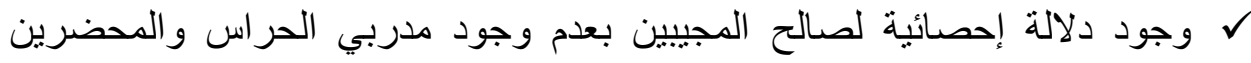

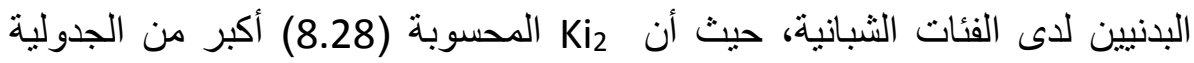

النتائج السابقة تبين بوضوح مدى الخلل الذي تعرفه مؤشرات التكوين الكروي

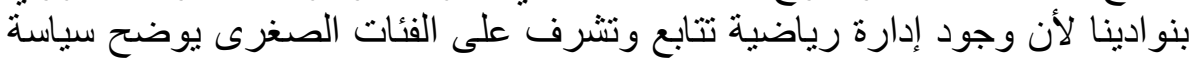

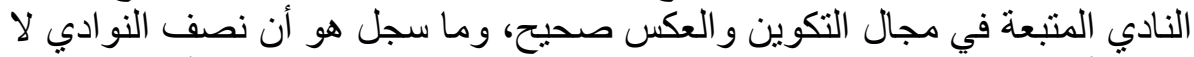

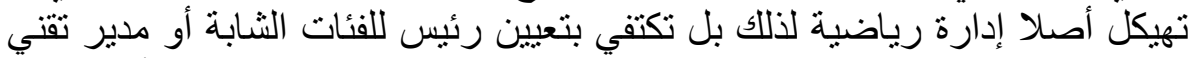

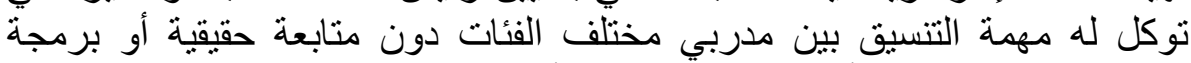

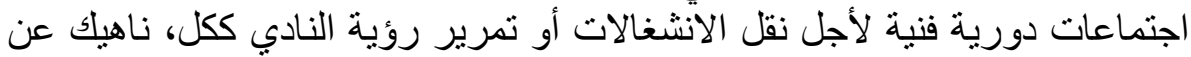

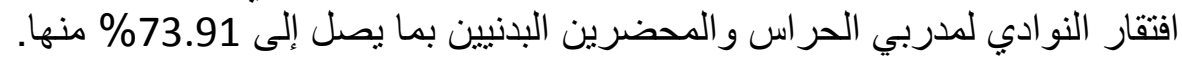

\section{1}

1.2.1. نتائج المحور الأول والثاني بالأندية التونسية: عرفت التون في مجملها نتائج

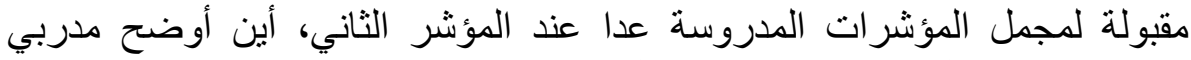
الفئات الصغرى للنو ادي التونسية عن المعطيات التالية: 
جدول رقم (03): يمثل بعض من نتائج المحورين الأول و الثاني بالنو ادي التونسية.

\begin{tabular}{|c|c|c|c|c|c|}
\hline القرار & محسوبة Ki & محسوبة Ki & التكرار & العبارات & المؤشر \\
\hline \multirow[t]{4}{*}{ دال } & \multirow[t]{4}{*}{7.81} & \multirow[t]{4}{*}{9.78} & 00 & فر في & \multirow[t]{4}{*}{ واقع الأندية } \\
\hline & & & 08 & تحسن & \\
\hline & & & 05 & متوسط & \\
\hline & & & 02 & لا إجابة & \\
\hline \multirow[t]{4}{*}{ غال } & \multirow[t]{4}{*}{5.99} & \multirow[t]{4}{*}{2.8} & 03 & غياب & \multirow[t]{4}{*}{ واقع تكوين } \\
\hline & & & 08 & الالامتئام & \\
\hline & & & 04 & غياب التأطير & \\
\hline & & & 00 & لا إجابة & \\
\hline \multirow[t]{4}{*}{ دال } & \multirow[t]{4}{*}{7.81} & \multirow[t]{4}{*}{9.78} & 05 & نعم & \multirow{4}{*}{ للثبان ميزانية } \\
\hline & & & 08 & $\gamma$ & \\
\hline & & & 02 & أحيانا & \\
\hline & & & 00 & لا إجابة & \\
\hline
\end{tabular}

من خلال النتائج المحصل عليها في الجدول رقم (03) سجل التالي:

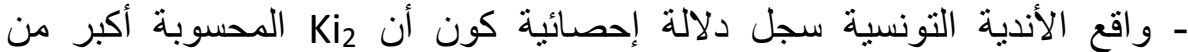

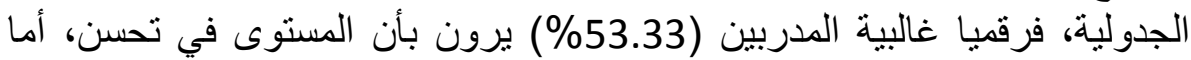
33.33 منهم فأوردو البأنها متوسطة.

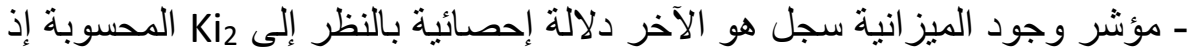

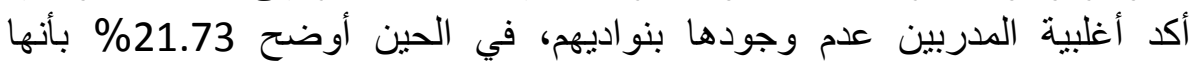

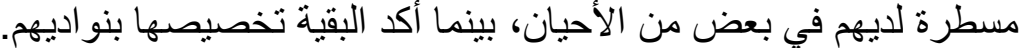

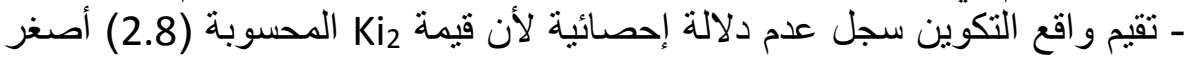
من الجدولية ، و هو ما يدل على اختلاف إجابات المدربين إذ نجد 20\%

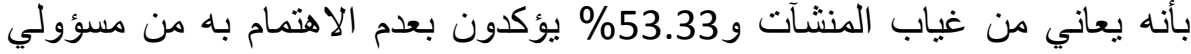

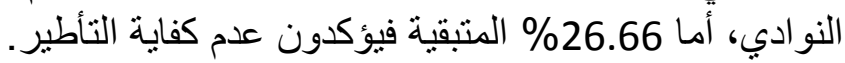

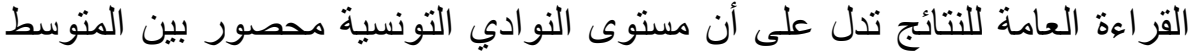

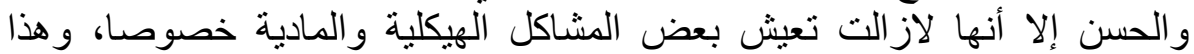


انعكس على نوعية تكوين شبان كرة القدم رغم أن بعض من الأندية التونسية تمتلك بنية تحتية مقبولة لتكوين الفئات الثبانية. 2.2.1. نتائج المحورين الثالث والرابع بالأندية التونسية: عرفت في مجملها نتائج سلبية لمجمل المؤشرات المدروسة، أينا أوضح مدربي الفئات الصغرى عن نقائص

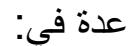
جدول رقم (04): يبين نتائج مؤشر ات المحورين الثالث و الر ابع بالنو ادي التونسية.

\begin{tabular}{|c|c|c|c|}
\hline النسبة المئوية & التكرار & الأجوية & المؤشر \\
\hline$\% 80.00$ & 12 & ن نعم & \multirow{3}{*}{ لرجياضية } \\
\hline$\% 13.33$ & 02 & $y$ & \\
\hline$\% 6.66$ & 01 & أحيانا & \\
\hline$\% 100$ & 15 & نعم & \multirow{2}{*}{ تقتي } \\
\hline 00 & 00 & $y$ & \\
\hline$\% 100$ & 05 & أقل من 6 & \multirow{3}{*}{ الاجنتميـة الاعات } \\
\hline \multirow[t]{2}{*}{00} & 10 & أكثر من 6 & \\
\hline & 00 & لا توجد & \\
\hline$\% 86.66$ & 13 & نعم & \multirow{2}{*}{ وبرني محدرب } \\
\hline$\% 13.33$ & 02 & $y$ & \\
\hline
\end{tabular}

من خلال النتائج المحصل عليها في الجدول رقم (04) تجلى الآتي ذكره: مؤشر وجود إدارة رياضية خاصة بالنوادي التونسية وصل إلى الىلى 80\% من مجمل العينة، أي أنها نسبة كبيرة وجد معتبرة تبرز نو عا ما الاهنمام بمتابعة الفئات الثبابية. ل فيما يخص جانب العمل بالتنسيق مع مدير تقني خاص بالإشر اف و المتابعة، سجلت نسبة كاملة من الإجابات بما يسمح من عقد أكثر من 06 اجتماعات سنوية

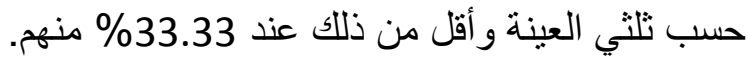
ل إجابات مدى استفادة الفئات الصغرى من مدربي الحراس والمحضرين البدنيين أوضحت أن نسبة 86.66\% من النوادي التونسية تمتلكها على مستوى من مدرب طو اقمها الفنية، أما 13.33\% فقد أوضحت بأن الفئات الصغرى لا تستفيد من هذا

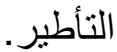

مجمل النتائج المحصل عليها توحي بفكر ايجابي مقبول لاى مسؤولي الأندية التونسية

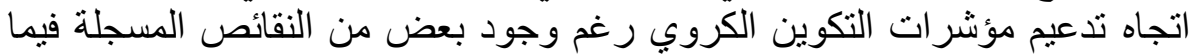

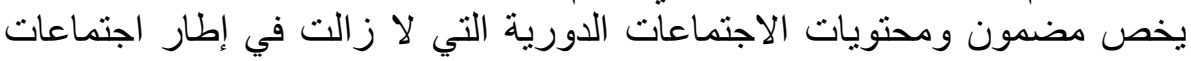
عادية لا تناقش مو اضيع تدريبية فنية بحتة. 
3.1. نتائج مؤشر عدد اللاعبين المكونين في النوادي الجزائرية والتونسية: ارتأينا

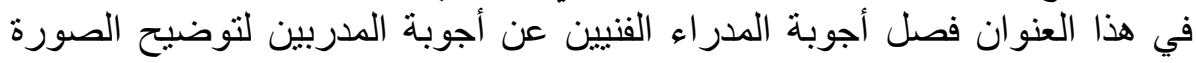

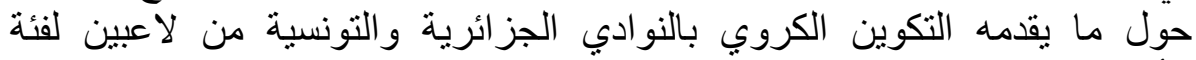
الأكابر ، وكانت النتائج المحصلة كانئ التالي:

أ/ عرض نتائج عدد اللاعبين بالأندية الجزائرية:

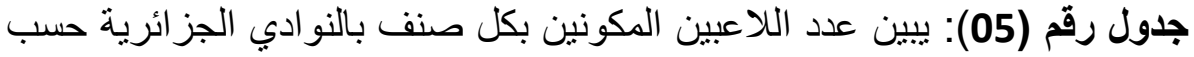

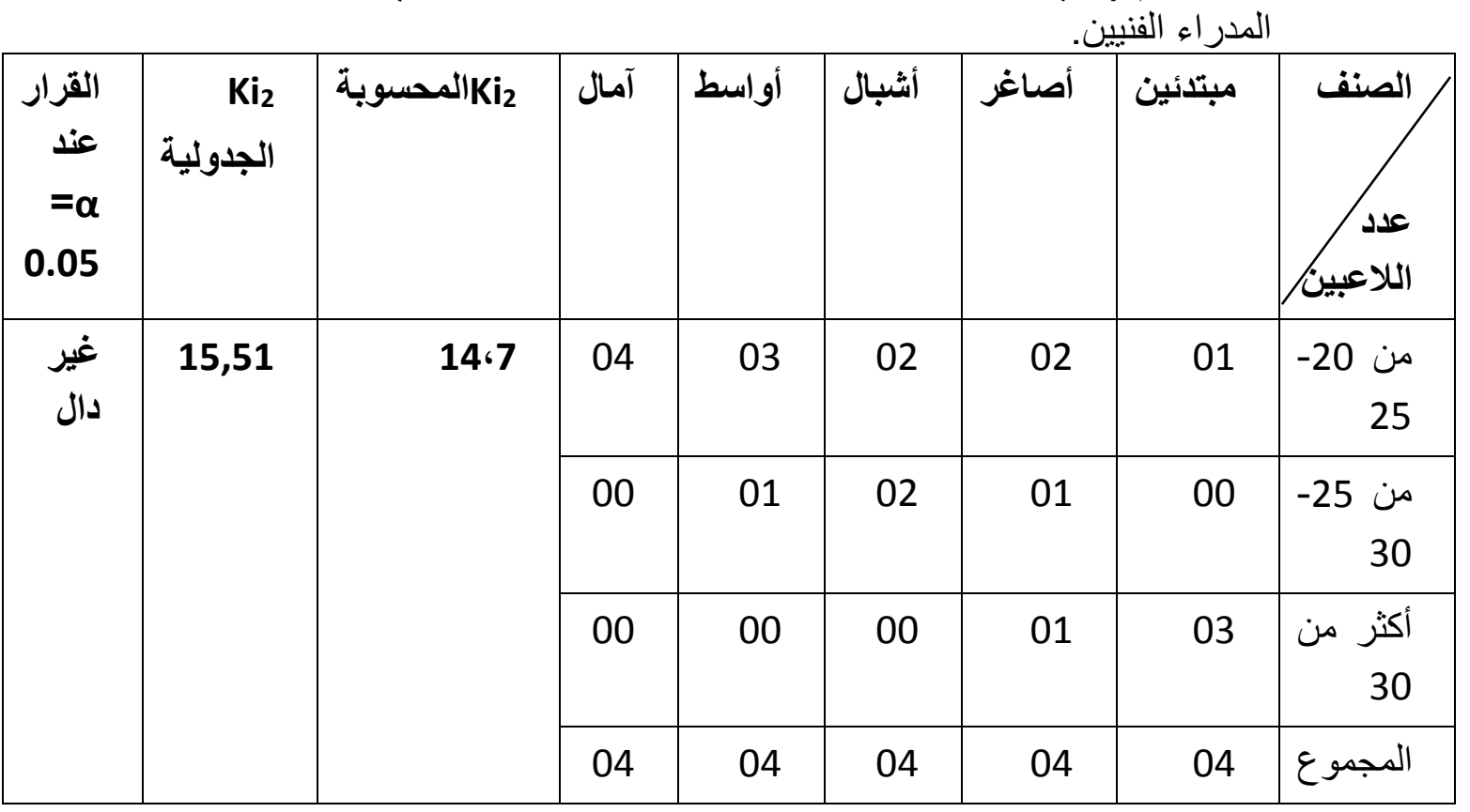

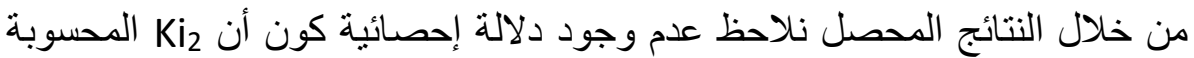

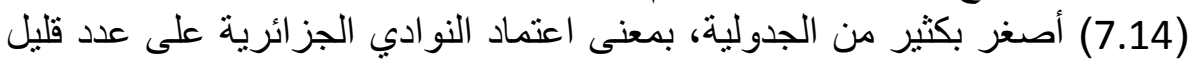
من شبان كرة القدم في كل الأصناف بما يضعف إمكانية وصول لإندان لاعبين مهاريين

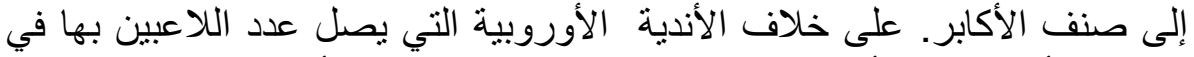

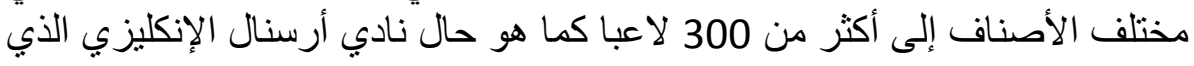
يستقبل سنويا 1000 لاعب في مختلف المر احل العمرية.

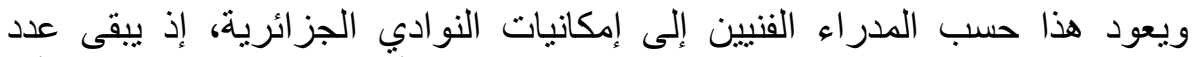

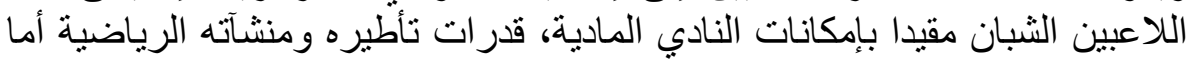

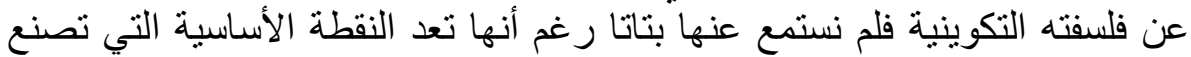
الفارق بين ناد مكون وناد آخر غير كذللك. 
أ/ عرض نتائج عدد اللاعبين بالأندية التونسية:

جدول رقم (06): يمثل عدد اللاعبين المكونين بكل صنف بالائل بالنو ادي التونسية حسب

\begin{tabular}{|c|c|c|c|c|c|c|c|c|}
\hline & & & & & \multicolumn{4}{|c|}{ المدر اء الفنيين. } \\
\hline $\begin{array}{r}\text { عند } \\
=\alpha \\
0.05 \\
\text { ع } 0.05\end{array}$ & الجدولية & Ki2 & آمال & أواسط & أشبال & أصاغز & مبتدئين & اللاعبين/ \\
\hline \multirow[t]{4}{*}{ غير } & \multirow[t]{4}{*}{$51 \cdot 15$} & \multirow[t]{4}{*}{$01 ، 3$} & 02 & 02 & 01 & 01 & 00 & 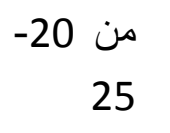 \\
\hline & & & 01 & 01 & 00 & 01 & 02 & 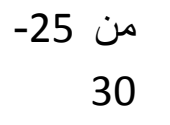 \\
\hline & & & 00 & 00 & 02 & 01 & 01 & أكثر من \\
\hline & & & 03 & 03 & 03 & 03 & 03 & المجموع \\
\hline
\end{tabular}

من خلال النتائج المحصل بالجدول رقم (06) نلاحظ عدم وجود دلالة إحصائية لأن Ki2

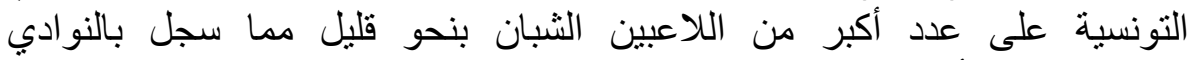
الجزائرية، إلا أن ذلك ييقى غير كاف لوصول عدئ عدد من اللاعبين المهاريين إلى بلى التي

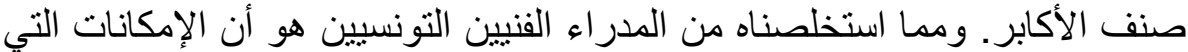

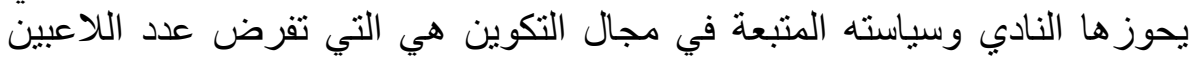

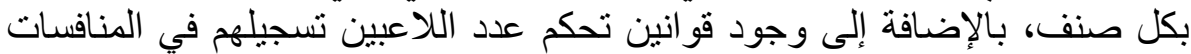
الرسمية للفئات الثبانية. 4.1. نتائج مؤشر حصول اللاعبين الشبان على عقود ومنح مادية في إطار جدول رقم (07): العقود والمنح المادية لشبان المكونين بالأندية الجزائرية

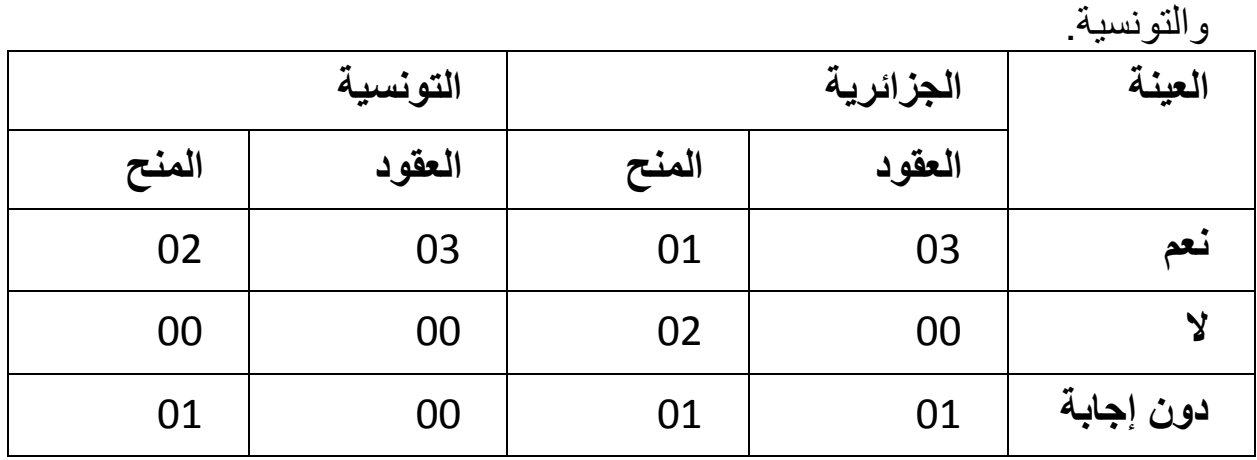

نلاحظ مما سبق أن أغلبية المدر اء الفنبين الجزائربين والتونسبين أكدوا وجود عقود

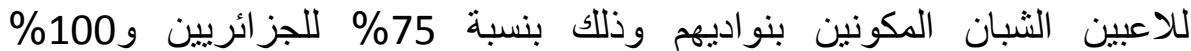
للتونسيين، أما عن المنح فوجد بأن 50\% من النوادي الجزائرية لا تقدم أي 
تحفيزات مادية للاعبين المكونين لديها، في الحين أن 66.66\% من النوادي مني

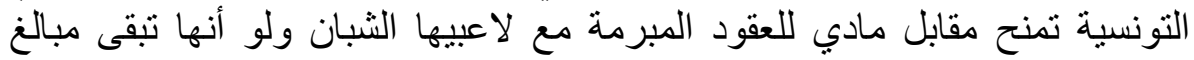
رمزية إلا في بعض الاستثناءات الحادة العادي.

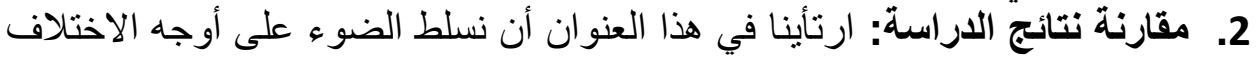

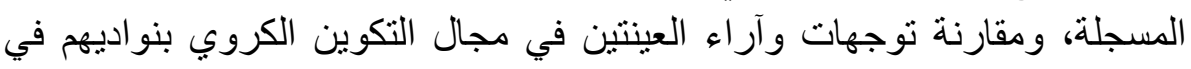

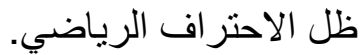
1.2. مقارنة نتائج محوري تقييم التكوين والهياكل والإمكانات المادية: جدول رقم(08): أوجه الاختلاف المسجلة في المحورين الأول والثاني.

\begin{tabular}{|c|c|c|c|}
\hline التوادي & النوادي & الأسئلة & مؤشرات المحور \\
\hline تحسن مسجل. & تر اجع رهيب. & مستوى التكوين & \multirow{2}{*}{ تقتيمين } \\
\hline في النوادي. & في الأكاديمية. & التكوين الأمثثل & \\
\hline محيز انية خاصة & عديز انية وجود & الميزانية الخاصة & \multirow{4}{*}{ الإمكانات المادية } \\
\hline الهياكل & الرياضية. الهياكل & الهياكل والمنشات & \\
\hline النادي فقط. & الوزارة & التيوين & \\
\hline تر اعى & لا تر اعى & التلاريب المسافة بين مركز & \\
\hline
\end{tabular}

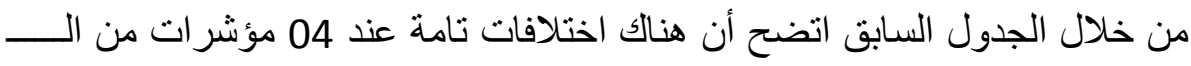

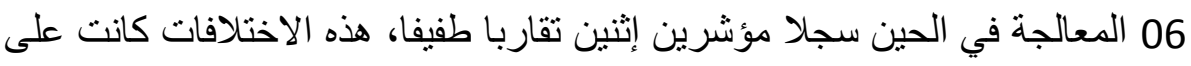

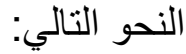
أ/ مؤشر تقييم مستوى التكوين : حيث تم تسجيل مايلي:

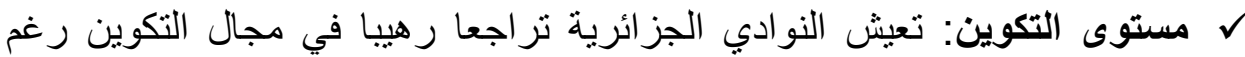

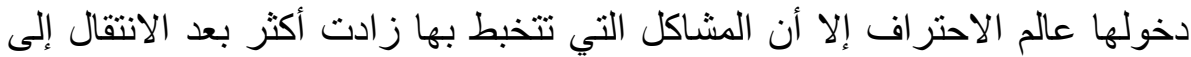

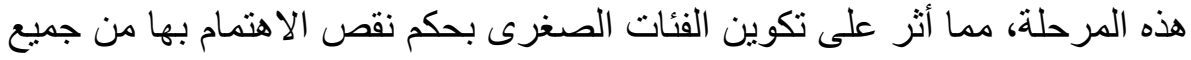

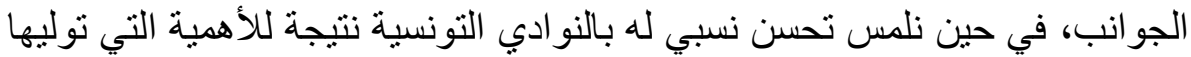
بعض أنديتها المحترفة للعمل القاعدي المستقبلي.

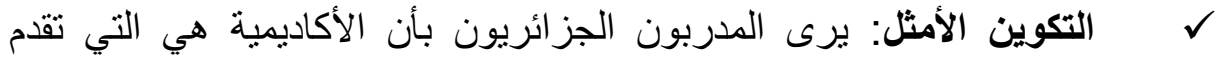

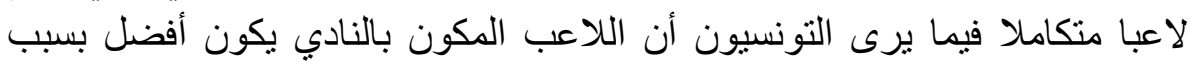

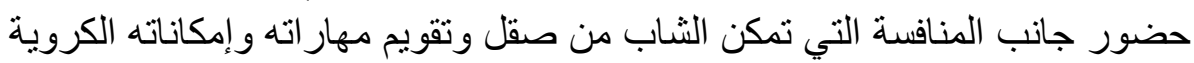
بصفة أحسن. ب/ مؤشر الإمكانات المادية والهياكل الرياضية: شملت جملة اختلافات نوجزها في

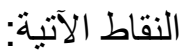


الميزانية الخاصة: تبقى الميزانية الخاصة الموجهة لفائدة الفئات الصغرى

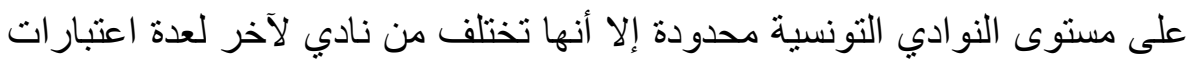

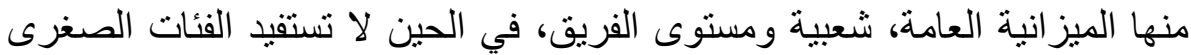

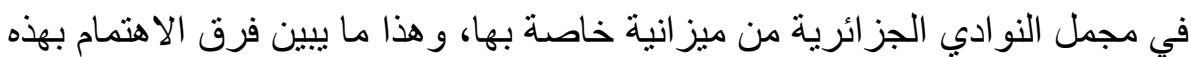
الفئات بين النو ادي التونسية و الجزائرية.

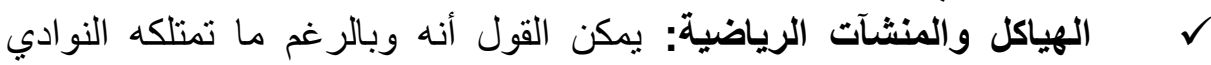
التونسية من هياكل ومنشآت رياضية (الترجي الرياضي التونسي والإنية الإفريقي مثنلا)،

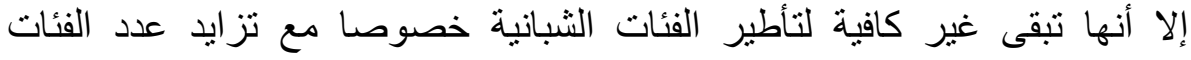

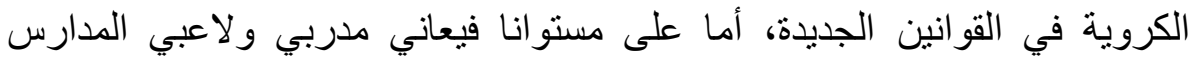

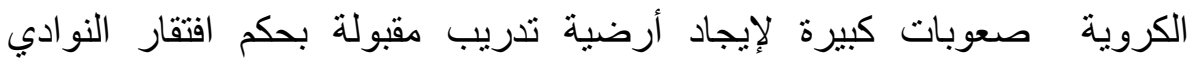

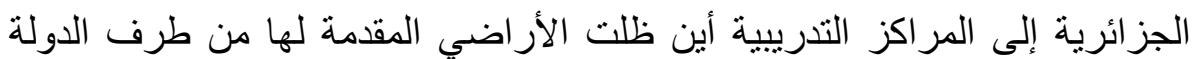
تتنظر تشبيد المر افق الرياضية.

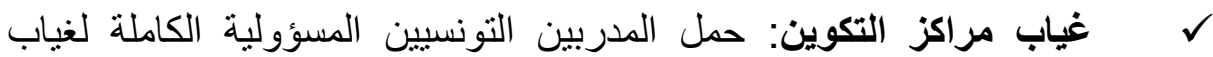

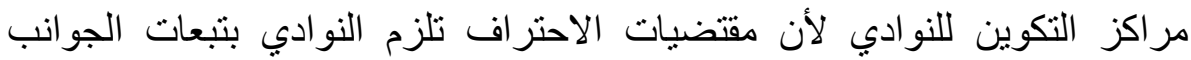

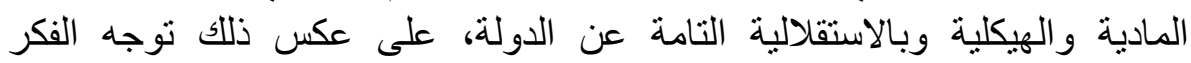

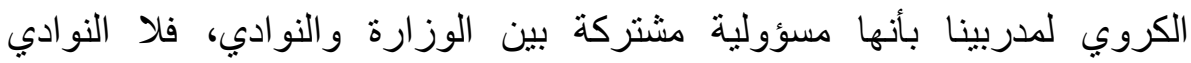

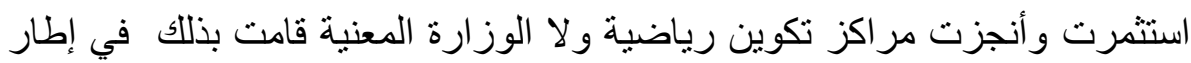
البرامج الوطنية للتطوير الرياضي.

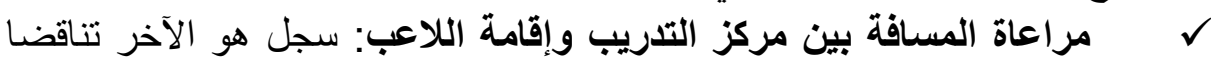

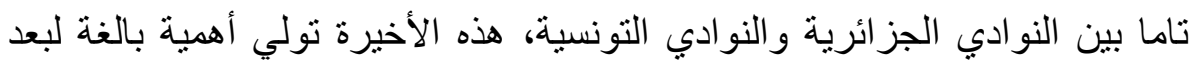

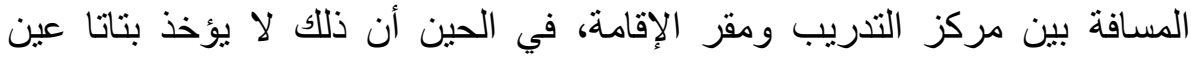

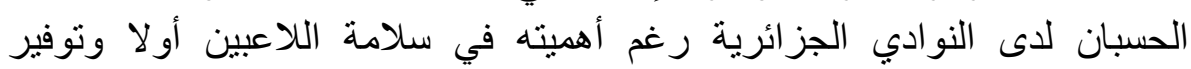
جهودهم ثانيا.

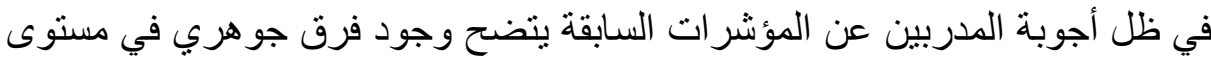
الاهتمام بتفاصيل التكوين من جو انبه الهيكلية والمادية لصالح الأندية التونسية. 
2.2. مقارنة نتائج محوري تأطير التكوين وبرامجه: جدول رقم(09): يوضح أوجه الاختلاف المسجلة في المحوري الثالث و الر ابع.

\begin{tabular}{|c|c|c|c|}
\hline النوادي التونسية & الجزائريـة النية & الأسئلة & مؤشرات \\
\hline 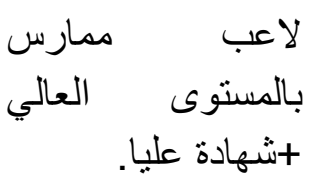 & شهادة تدريبية. ممارس+ & التمط المناسب & \multirow[t]{4}{*}{ تأطير } \\
\hline والأهداف. الإدارة دون & لا توجد & وإدارة & \\
\hline مرة في الأسبوع & مرة في الثهر & والاجتماعات & \\
\hline موجود & نسبي و غير كاف & التتابيرة التعليمية و & \\
\hline محدود إلا بالفئات & $\begin{array}{r}25 \\
\text { إلى } 30\end{array}$ & فئة عد اللاعبين بكل & \multirow{5}{*}{ التكوين } \\
\hline$\% 50$ & $\% 20$ & المكون المنفادة المنادية & \\
\hline$\% 40$ & $\% 20$ & نسبة الاستفادة من المبين & \\
\hline$\% 80$ & $\% 40$ & أخرى التبية & \\
\hline مبرمجة أحيانا. & غير مبرمجة & الحصص النظرية & \\
\hline
\end{tabular}

من خلال نتائج الجدول أعلاه تجلت اختلافات تامة عند 07 مؤشرات من 09 المعالجة، في الحين سجل المؤشرين المتبقيين تقاربا نسبيا في طرحهما، هذهاء الاختلافات كانت على النحو التالي: أ/مؤشر تأطير التكوين: توقفنا على عدة اختلافات تمثلت في:

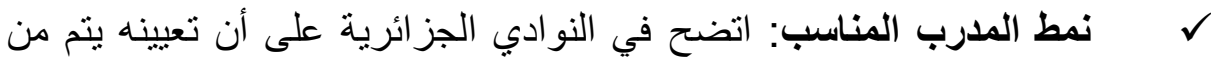

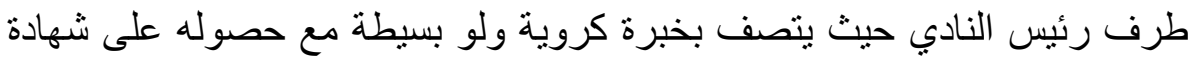
تدريبية دون تحديد مستوياتها، عكس النوادي التونسية التي تعتمد على لاعبين قدماء بصفة الدوليين من ذوي الثهادات التدريبية العليا وباختيار وتعبين من المدير الفئين الفني للفريق. 
ل وجود الإدارة الرياضية والأهداف المحددة: اتضح أن الخطط التدريبية لشبان

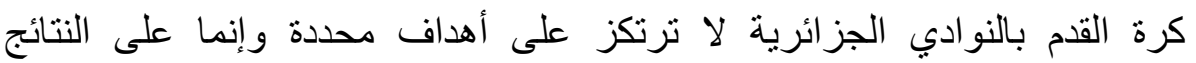

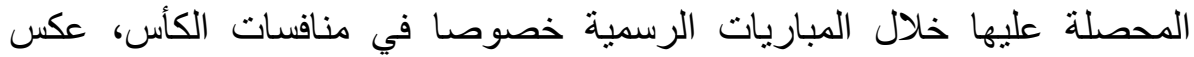
النوادي التونسية التي نصبت إدار ات رياضية شبانية على مستوى هياكلها الداخلية

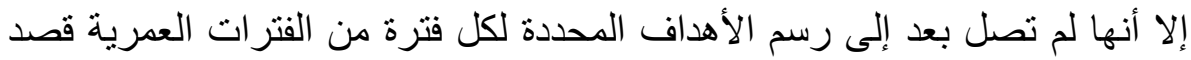

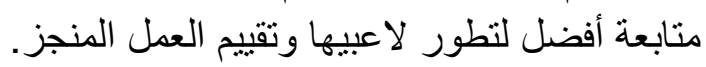

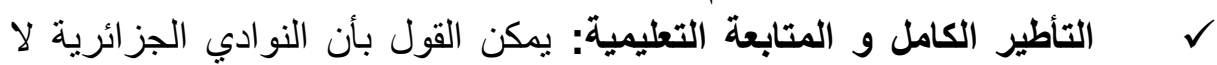

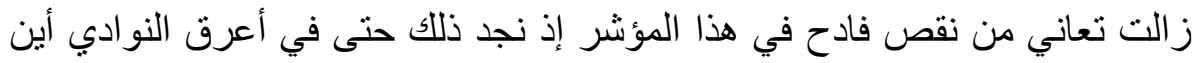

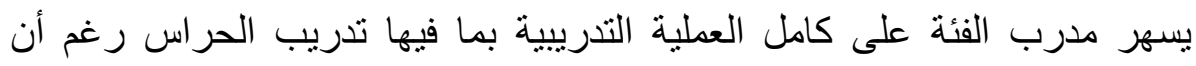

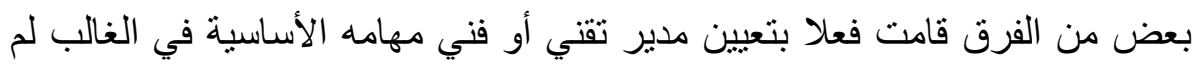

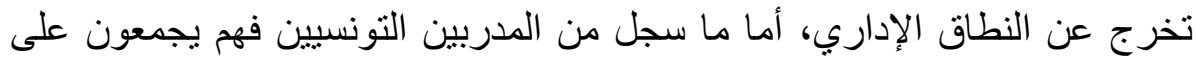

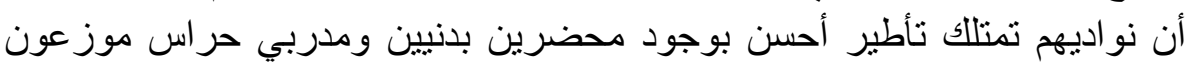

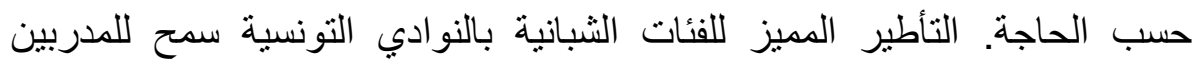

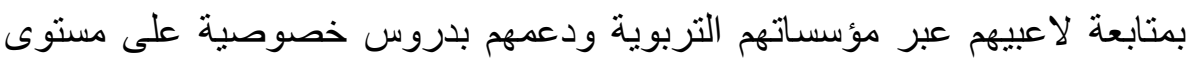

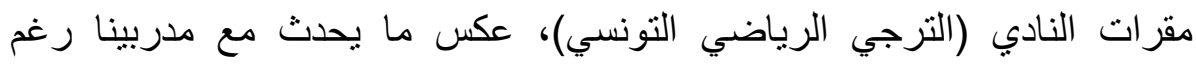

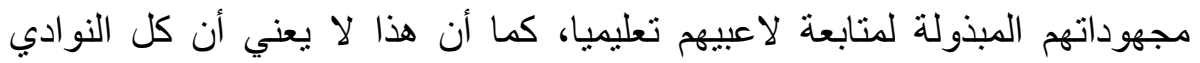

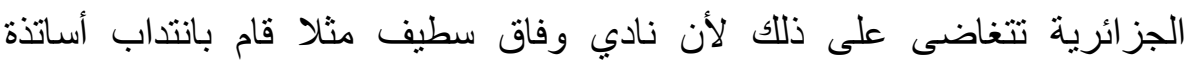

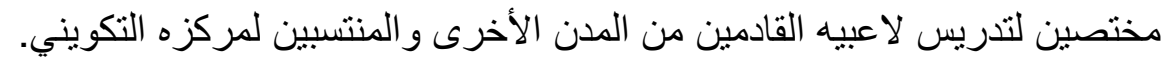

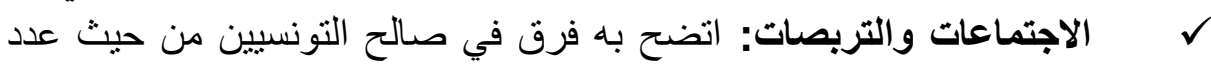

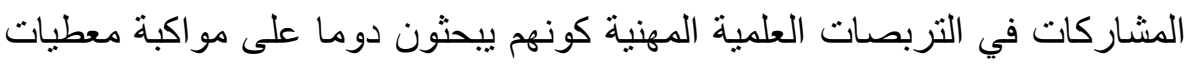

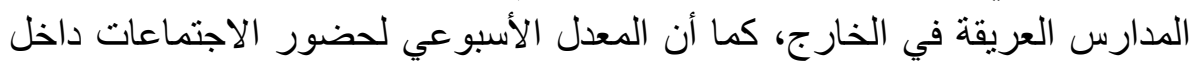

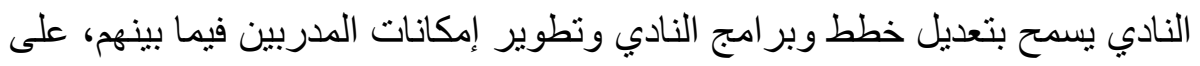

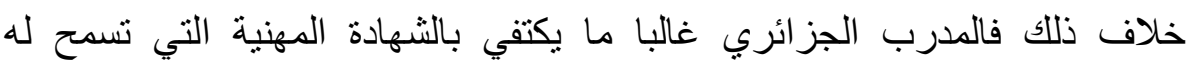

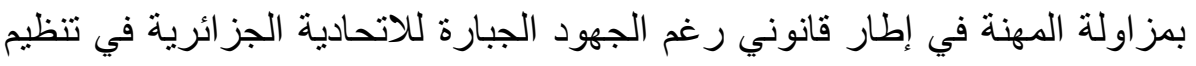

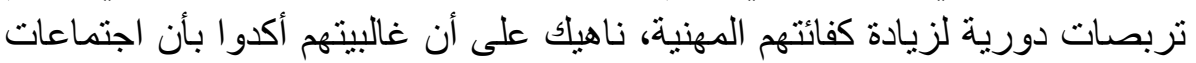

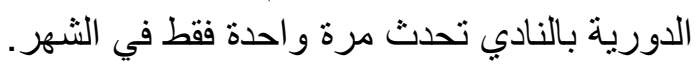

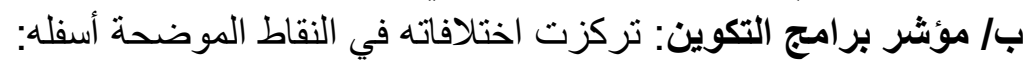

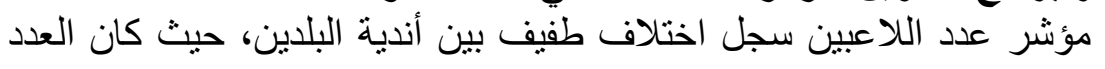

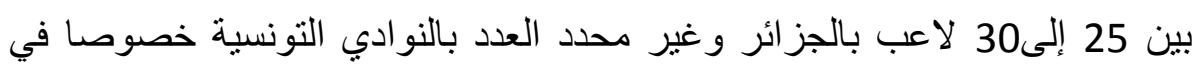

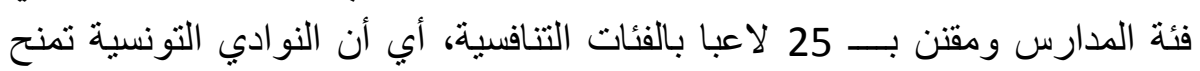
لنفسها فرصة أكبر في انتقاء وتكوين المواهب الثابة من خلال عدد أكبر للأطفال

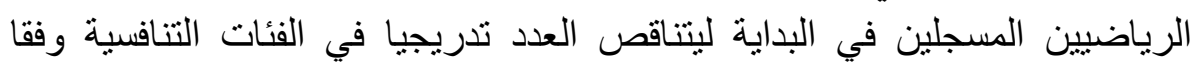

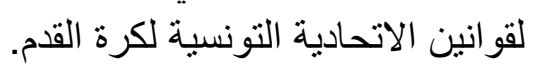

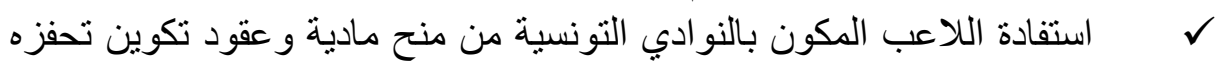

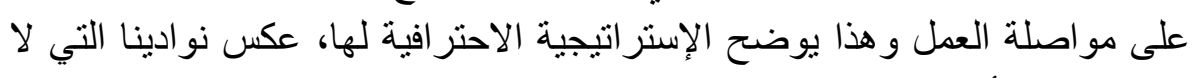

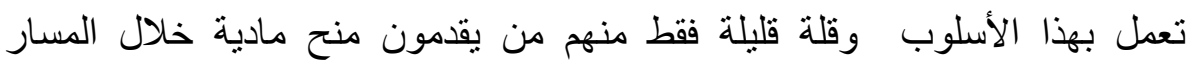
التكويني للثبان. 
نسبة استمر ار اللاعبين بلغت بالنوادي الجزائرية 40\% في الفئات الصغرى

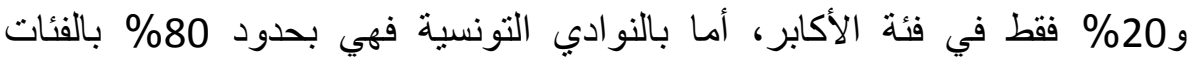
الصغرى و40\% في الأكابر.

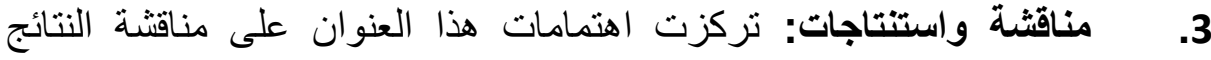

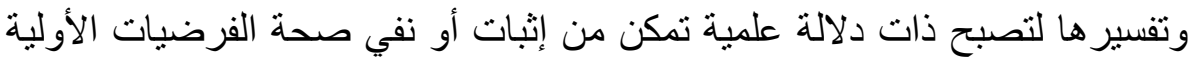

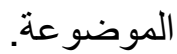

نصت الفرضية الأولى على أن التكوين بمدارس كرة القدم التونسية المحترفة

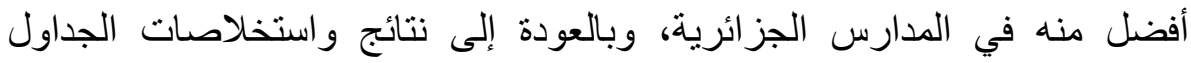

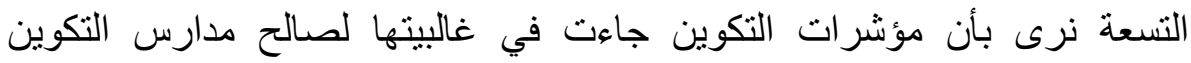
التونسية بما يعني صحة الفرض البحثي، حيث أجمع المدربون الجزائريون على كئى

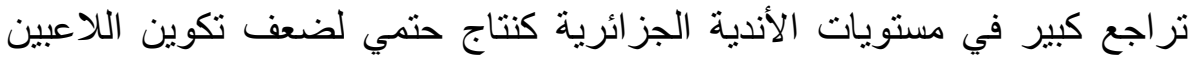

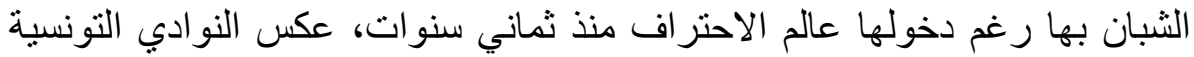

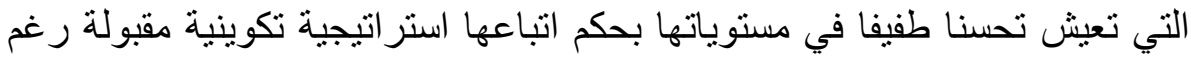
بعض النقائص المسجلة بها.

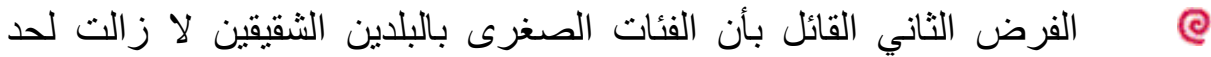

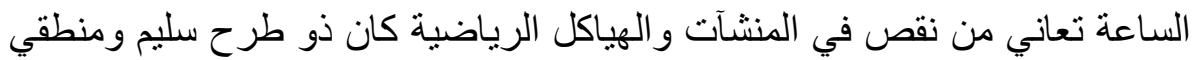

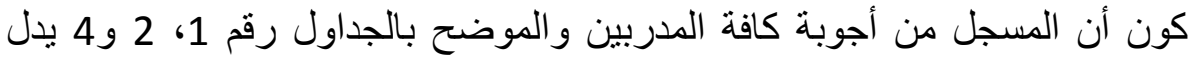
على نقص كبير بها لدى النوادي الجزائرية و عدم كفايتها بالنو ادي التونسية.

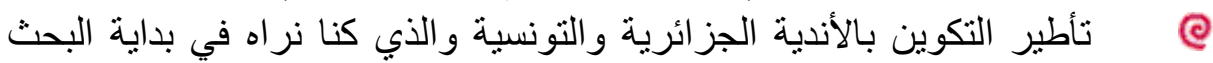

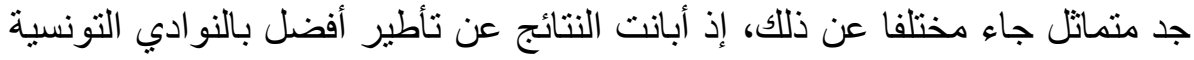

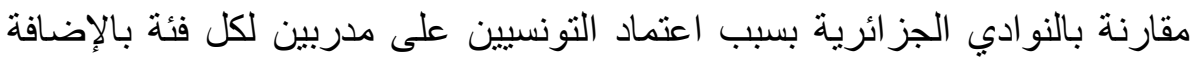

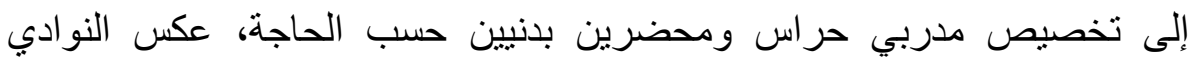
الجزائرية التي لا زالت تعتمد في أغلب الأحيان على مدرب واحد لكل فئة، وهو ما

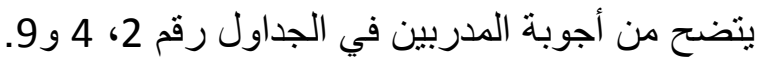

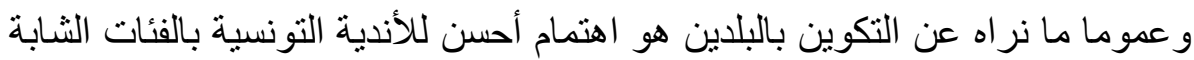

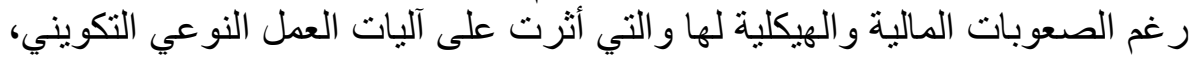

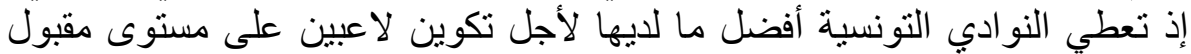

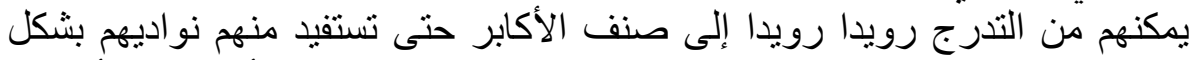

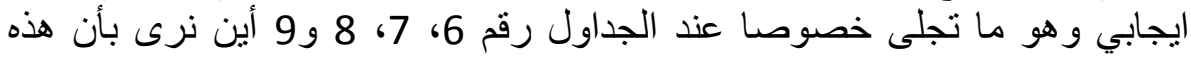
الاستراتيجية سمحت باستقطاب عدد كبير من الثبان في الفئات الأولى ليتمكن النادي

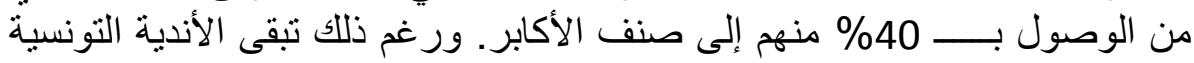

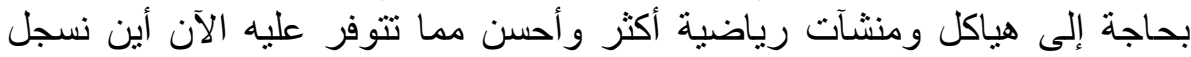
مثلا أن مدرسة كرة القدم أو أكاديمية ليفربول لأقل من 16 سنة تمنلك 13 أرضية

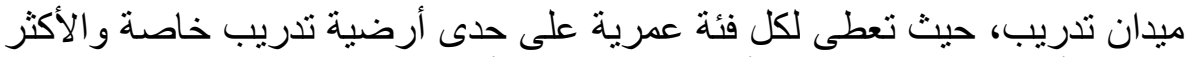

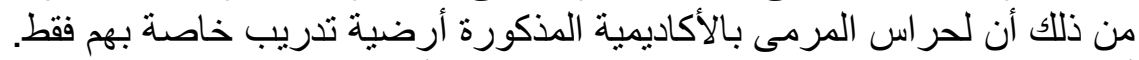

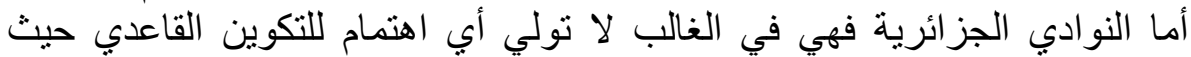

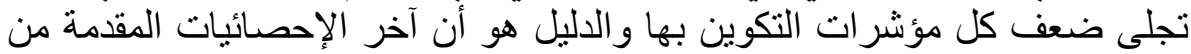

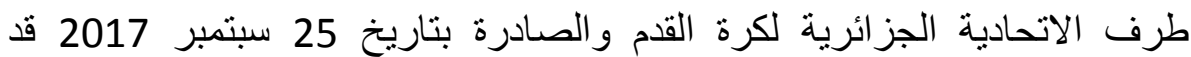

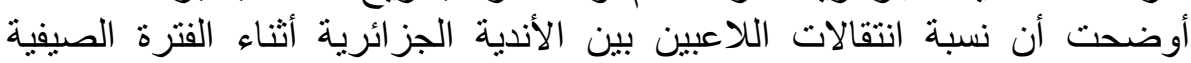
وصلت إلى 75\% بمعنى الاعتماد الكلي على اللاعب الجاهز لأجل تحقيق النتائج 
في ظل صعوبة دمج اللاعبين الثبان في صنف الأكابر ارتباطا بمستوياتهم التي

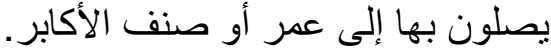

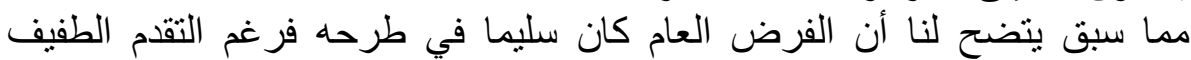
للتكوين بالمدارس التونسية إلا أن كلا البلدين لا زال التكان التكوين بهما لحد الساعة بعيدا عن المستوى المأمول هيكليا وفنيا. 4. اقتراحات وتوصيات : في ضوء وله الدراسة النظرية والميدانية للبحث نقترح

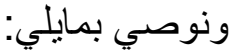
ل ل وضع الكفاءة الكروية المناسبة على جميع المستويات والمسؤوليات بالكرة

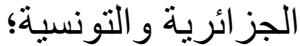
ل إيجاد سياسة رياضية ناجعة ودقيقة لإعادة مسار التكوين الكروي إلى سكته

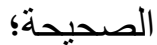

إعادة النظر في النصوص المتعلقة بتنظيم، تسيير وتمويل أندية الاحتراف

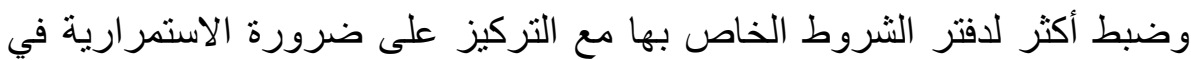

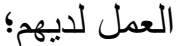
ل ل التخطيط لإنشاء مر اكز التكوين الرياضي عبر كافة أقطاب القطر الجزائري والتونسي؛ ل إعادة النظر في نظام البطولة الموجه لشبان كرة القدم وتأهيل مدربيهم أكثر علميا ومنهجيا. الخاتمـة: قد أردنا في دراستنا هذه معالجة جانب مهم من جوانب التقدم والتطور

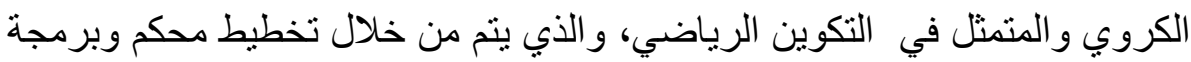
تدريبية متناسقة الأهداف مع السهر الدائم للقائمين على الثؤون الكروية على مر اقبة

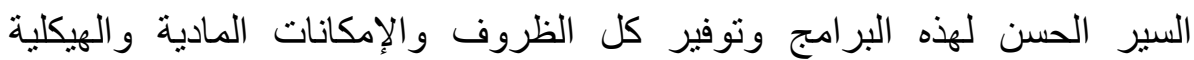
المساعدة لذلك في إطار تربوي تعليمي طويل المدى. لئ.

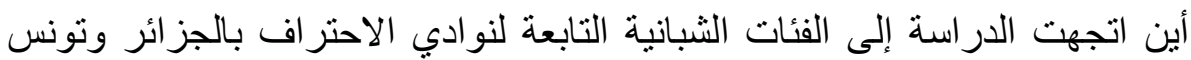

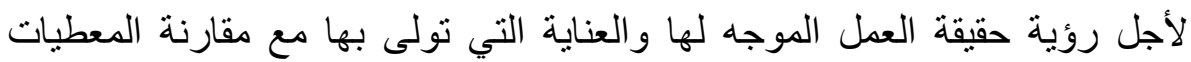

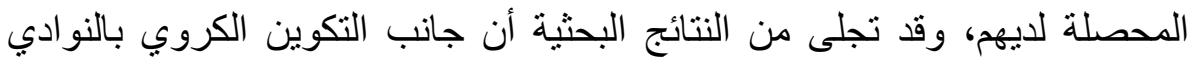

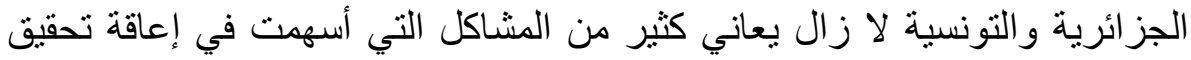

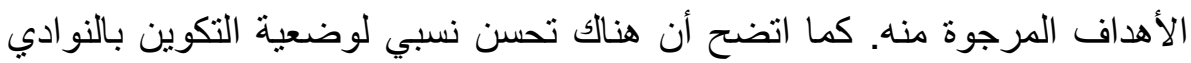

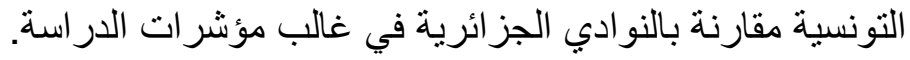


1) محمد عبد الحميد (2000): البحث العلمي في الدراسات الإعلامية، ط1، عالم

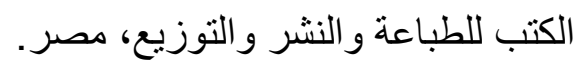

2) محمد منير حجاب (2002): أساسيات البحوث الإعلامية والاجتماعية، ط3، دار الفجر، القاهرة، ،ص36.

3) محمد زيان عمر (1983): البحث العلمي وتقنياته، ديوان المطبوعات الجامعية،

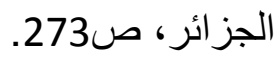

4) سامي عريفج؛ خالد حسين (1999): مصطلح في منهاج البحث العلمى وأساليبه،

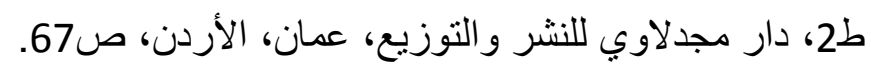

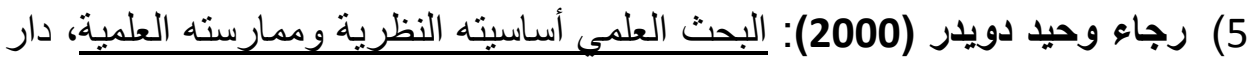

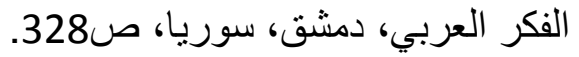

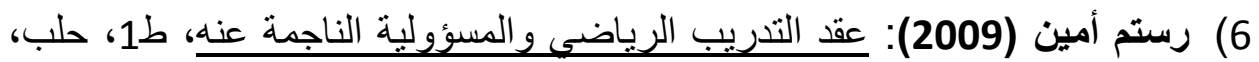
سوريا. 7) إيريك بييت (2010): تكوين لاعب كرة القدم الهاوي: الإثنو غر افيا الاجنماعية لبناء

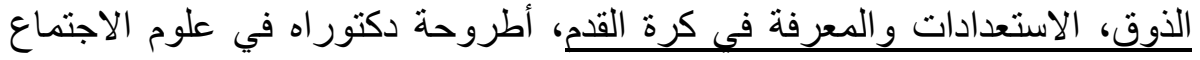
و التربية، جامعة فيكتور سيغالون، بوردو 2؛ فرنسا.

8) CLAUDE BAYER (1982): La Formation des joueurs De Handball, Ed Vigot، Paris.

9) SAMBA DIOUF (2009): Réflexion Sur La Qualité De La Formation Des Jeunes Footballeurs Dans Les Centres De Formation Du Football Au Sénégal, Mémoire du Fin D’étude, Dakar, SENEGAL.

10)PIERRE MIRALLES (2005): Les Nouvelles Stratégies Du Club De Football Professionnel Face à La Guerre Des Talents، Revue International Sur Le Travail Et La Société, Paris. 